\title{
Global and local perceptual style, field-independence, and central coherence: An attempt at concept validation.
}

\author{
Elizabeth Milne $e^{1}$ and Marcin Szczerbinski²
}

\begin{abstract}
'Department of Psychology, the University of Sheffield, Western Bank, Sheffield, S10 2TP, UK
${ }^{2}$ Department of Human Communication Sciences, the University of Sheffield, 31 Claremont Crescent, Sheffield S10 2TA, UK
\end{abstract}

ABSTRACT

Historically, the concepts of field-independence, closure flexibility, and weak central coherence have been used to denote a locally, rather globally, dominated perceptual style. To date, there has been little attempt to clarify the relationship between these constructs, or to examine the convergent validity of the various tasks purported to measure them. To address this, we administered 14 tasks that have been used to study visual perceptual styles to a group of 90 neuro-typical adults. The data were subjected to exploratory factor analysis. We found evidence for the existence of a narrowly defined weak central coherence (field-independence) factor that received loadings from only a few of the tasks used to operationalise this concept. This factor can most aptly be described as representing the ability to dis-embed a simple stimulus from a more complex array. The results suggest that future studies of perceptual styles should include tasks whose theoretical validity is empirically verified, as such validity cannot be established merely on the basis of a priori task analysis. Moreover, the use of multiple indices is required to capture the latent dimensions of perceptual styles reliably.

\section{INTRODUCTION}

The aim of the present study was to explore the factorial structure of visual perceptual styles. We did this by identifying tasks within the literature that are described as measuring perceptual style and carrying out exploratory factor analysis.

The human visual system excels at object recognition: Objects within the visual scene are identified and perceived as wholes, even when the relevant perceptual data are incomplete. This is demonstrated by the ease with which we can identify familiar objects from incomplete line drawings (Street, 1931), or recognise faces from partially represented black and white forms (e.g., Mooney, 1957). Such abilities are said to be underpinned by a drive for perceptual closure. A related example of closure is seen in contour illusions (e.g., Kanizsa, 1974) in which, due to the organisation of local elements, boundaries and contours are perceived despite not being physically present. This tendency to group features together into a "good form" was identified as the basic law of perception by the Gestalt School of Psychology (the law of prägnanz) and highlighted that elements that are proximal to one another or that share a common property (shape, size, colour, orientation, movement in the same direction, etc.) are subject to perceptual grouping. So strong is the tendency to group visual features that it is often difficult to disambiguate constituent local features from a cluttered array. This is demonstrated by difficulty in tasks such as "spot the differences" and is especially effortful when the local features to be detected are embedded within a more complex figure, as in the Embedded Figures Test (Witkin, Oltman, Raskin, \& Karp, 1971). Even when the local features are self contained and not embedded in the surrounding context, the perception of the global form still dominates (Navon, 1977).

Please address correspondence concernig this article to either author at e.milne@sheffield.ac.uk, tel: + 44 (0) 114 2226558; m.szczerbinski@sheffield.ac.uk, tel: + 44 (0) 1142224229 . 
Despite evidence suggesting a universal bias towards perceptual grouping, and a tendency to perceive the global before the local details, individual variation in the drive for global precedence is also evident. Witkin et al. coined the terms field-dependence and field-independence (Witkin, Dyk, Faterson, Goodenough, \& Karp, 1962) to classify such individual differences. An individual who is field-dependent is highly influenced by the context of the visual scene when processing features, whereas a person who is field-independent is more able to perceive an element independently from its context. The concept of field-(in) dependence was investigated with paradigms such as the Rod and Frame Test (Witkin \& Asch, 1948) in which a rod is placed within a tilting frame and participants are required to adjust the rod so that it is upright. This task is accomplished most successfully by participants who can perceive the orientation of the rod independently from the angle of tilt of the frame, that is, participants who are able to resist cues from the surrounding context when making perceptual judgements.

Performance on the Rod and Frame Test correlates highly with that of the Embedded Figures Test (Witkin et al., 1962). The latter is still frequently used in research, and has a range of applications, for example to investigate perceptual style for the purposes of employee psychometric testing (Chapman \& Calhoun, 2006), to investigate perceptual styles across cultures (Nisbett \& Miyamoto, 2005), and in developmental research, especially in the field of atypical development and autism (Shah \& Frith, 1983). Frith $(1989,2003)$ coined the term weak central coherence to describe the clinical and experimental observation that individuals with autism often appear to ignore the (global) aspects of the visual scene that would be most salient to a typical observer, instead showing a tendency to focus on the smaller details, and a reduced ability to integrate material into appropriate context. Since the notion of central coherence was introduced, numerous studies have demonstrated weak central coherence in autism, although the range of tasks used to measure this is varied. For example, children with autism have been shown to succumb to the Gestalt principle of proximity significantly less than controls (Brosnan, Scott, Fox, \& Pye, 2004) and to excel at the Embedded Figures Test (Shah \& Frith, 1983) and the Block Design sub-test from the WAIS (Shah \& Frith, 1993). They also show superior ability to spot differences within two similar visual scenes (Teunisse, Cools, van Spaendonck, Aerts, \& Berger, 2001), enhanced ability to detect targets within a visual search array (Jarrold, Gilchrist, \& Bender, 2005; Plaisted, O’Riordan, \& BaronCohen, 1998), a tendency to use a feature based, piecemeal strategy when copying the Rey-Osterrieth Complex Figure (Booth, Charlton, Hughes, \& Happé, 2003; Ropar \& Mitchell, 2001) and a superior ability to reproduce impossible, but not possible, figures (Mottron, Belleville, \& Menard, 1999). There is also some evidence that children with autism may be less susceptible than typically developing children to geometric illusions, such as the Muller-Lyer illusion, and contour illusions such as those formed by the Kanizsa triangle (Happé, 1996, although see Ropar \& Mitchell, 1999, and Milne \& Scope, 2008, for negative findings). The specific demands of the above tasks are wide ranging, however, and the exact nature of processes that can legitimately be subsumed under a single label of central coherence remains to be es- tablished. As the list of studies above illustrates, the term weak central coherence is often used to describe tasks that favour local over global processing styles, although this is an extension of the original concept.

Witkin et al. (1962) reviewed a series of existing correlational and factor analytic studies, and concluded that field-independence was a narrow construct that refers specifically to the "ability to separate an item from its context" (p. 47). In other words, an item must be embedded within a structured context rather than merely being surrounded by amorphous material. This early research highlighted that field-independence is separate from the ability to identify an incomplete figure, as measured by Gestalt Completion tests (e.g., Street, 1931; Mooney, 1957). Tasks requiring identification of incomplete figures were only weakly related to those that required dis-embedding, and loaded onto separate factors described as measuring "speed of closure" (Thurstone, 1944).

A unique perspective is given by Carroll (1993) who described the structure of human cognitive abilities on the basis of a comprehensive survey and re-analysis of available correlational datasets. The outcome of this analysis with respect to the visuo-spatial domain is summarized in Table 1. Theoretically, Carroll's position is consistent with Witkin's as he identified the factor of Closure Flexibility (defined as the speed of disembedding a known stimulus array from a more complex array) which broadly corresponds with Witkn's notion of field-independence. The operationalisation of the two constructs is somewhat different, however. Whereas Witkin et al. (1962) used the Embedded Figures Test and Block Design to measure field-independence, Carroll demonstrated that closure flexibility is measured with the Embedded Figures task, the Hidden Patterns task and Copying tests, while the Block Design test represents a separate factor of Visualisation.

In sum, the precise conceptual and operational definition of the construct of (weak) central coherence/field-(in)dependence, and its relationship to other dimensions of visual cognition remains unclear. While Carroll's meta-analysis confirms the existence of such a construct, it suggests a very narrow interpretation: Facility at dis-embedding a known stimulus array from a more complex array, labelled closure flexibility and measured primarily with the Embedded Figures Test. This is consistent with Witkin's definition of field-independence but narrower than the notion of weak central coherence which, in its research application, if not in Frith's original formulation, is used to describe a wide variety of tasks that represent a variety of distinct factors within Carroll's framework.

Surprisingly, despite the abundance of research on central coherence there has been little attempt to ascertain the degree to which the numerous tests that are currently used to investigate it really do measure the same construct. The research that is available finds little support for a unitary construct. For example, Pellicano, Maybery, and Durkin (2005) carried out a principle components analysis of data collected from 70 children aged between 4 and 5 who performed the Embedded Figures Test, a test of pattern construction (similar to the Block Design subtest from the WAIS), a visuo-motor integration task that required participants to copy and maintain the configuration of a series of images, and a task that required participants to detect target shapes embedded within a complex background (Figure-Ground Test). The analysis produced 


\section{TABLE 1.}

The Visual Perceptual Factors Identified in Carroll's Systematic Survey of the Factorial Structure of Human Cognitive Abilities

\begin{tabular}{|c|c|c|}
\hline $\begin{array}{l}\text { Factors whose existence was } \\
\text { reasonably well confirmed } \\
\text { through re-analysis of existing } \\
\text { datasets. }\end{array}$ & Definition & Tasks loading highly on the factor \\
\hline Visualisation & $\begin{array}{l}\text { The ability to comprehend imaginary movements in a } \\
\text { 3-dimensional space or the ability to manipulate objects in } \\
\text { imagination. }\end{array}$ & $\begin{array}{l}\text { Block Design and Object Assembly } \\
\text { (WAIS) } \\
\text { Block counting tasks } \\
\text { Block rotation tasks }\end{array}$ \\
\hline Spatial Relation & $\begin{array}{l}\text { The ability to perceive spatial patterns or to maintain } \\
\text { orientation with respect to objects in space. }\end{array}$ & $\begin{array}{l}\text { Visuo-spatial perspective tasks } \\
\text { Card Rotation Task } \\
\text { Flags and Figure Rotation }\end{array}$ \\
\hline Closure Speed & $\begin{array}{l}\text { orientation with respect to objects in space. } \\
\text { The ability to combine disconnected, vague visual stimuli } \\
\text { into a meaningful whole; to unify an apparently disparate } \\
\text { perceptual field into a single concept. }\end{array}$ & $\begin{array}{l}\text { Flags and Figure Rotation } \\
\text { Gestalt Completion Test } \\
\text { Street Pictures } \\
\text { Closure Test } \\
\text { Incomplete Pictures }\end{array}$ \\
\hline Closure Flexibility & $\begin{array}{l}\text { The manipulation of two configurations simultaneously } \\
\text { or in succession. Speed of detecting and dis-embedding a } \\
\text { known stimulus array from a more complex array. }\end{array}$ & $\begin{array}{l}\text { Embedded Figures Test } \\
\text { Hidden Patterns Test } \\
\text { Copying Test }\end{array}$ \\
\hline Perceptual Speed & $\begin{array}{l}\text { The ability to locate a unique item in a group of identical } \\
\text { items. Finding, in a mass of distracting material, a given } \\
\text { configuration which is borne in mind during the search. }\end{array}$ & $\begin{array}{l}\text { Cancellation tests } \\
\text { Finding "A"s Test } \\
\text { Comparison tests }\end{array}$ \\
\hline \multicolumn{3}{|l|}{$\begin{array}{l}\text { Factors whose existence and/or } \\
\text { cognitive interpretation was less } \\
\text { well confirmed }\end{array}$} \\
\hline Serial Perceptual Integration & $\begin{array}{l}\text { The ability to apprehend and identify a visual pattern } \\
\text { when parts of the pattern are presented serially or } \\
\text { successively at a high rate. }\end{array}$ & $\begin{array}{l}\text { Tests of integration of successively } \\
\text { presented (i.e., motion film) pictorial } \\
\text { material. }\end{array}$ \\
\hline Spatial Scanning & $\begin{array}{l}\text { Speed in visually exploring a wide or complicated visual } \\
\text { field. }\end{array}$ & $\begin{array}{l}\text { Maze Tracking speed } \\
\text { Map Planning Test }\end{array}$ \\
\hline Imagery & $\begin{array}{l}\text { Ability to form internal mental representations of visual } \\
\text { patterns, and to use such representation in solving spatial } \\
\text { problems. }\end{array}$ & $\begin{array}{l}\text { Paper Folding } \\
\text { Card Rotation } \\
\text { Hands and Bolts }\end{array}$ \\
\hline Length Estimation & The ability to compare length of lines or distances. & $\begin{array}{l}\text { Shortest Road Test } \\
\text { Estimation of Length Test }\end{array}$ \\
\hline Perception of Illusions & Resistance to illusions involving geometrical figures. & $\begin{array}{l}\text { Nearer Point Test } \\
\text { Shape and direction illusion } \\
\text { (Poggendorf, Wundt, \& Zollner) } \\
\text { Overestimation/Underestimation } \\
\text { illusions (Muller-Lyer) } \\
\text { Size contrast (Delboeuf, Ponzo, \& } \\
\text { Ebbinghous) }\end{array}$ \\
\hline Perceptual Alterations & $\begin{array}{l}\text { The rate at which one alternates between ambiguous } \\
\text { perceptions. }\end{array}$ & $\begin{array}{l}\text { Retinal rivalry reversals } \\
\text { Necker Cube }\end{array}$ \\
\hline
\end{tabular}

two factors: one received loadings from the Pattern Construction Task and Visuo-Motor Integration, and the other received loadings from the Embedded Figures Test and the Figure-Ground Test, although the loadings on this factor were not in the expected direction as faster times on the Embedded Figures Test were associated with low scores on the Figure-Ground Test. These data suggest that the four selected tasks do not represent a unitary construct or a coherent index of perceptual style. Another, larger scale study investigated cross-domain perceptual styles in 204 children and adolescents (Booth, 2006). Four low-level visuo-spatial tasks were administered: Embedded Figures Test, Block Design, classification of possible and impossible figures, and a version of the Navon Hierarchical Figures Test. Two principle components were identified. The first received loadings from the Embedded Figures and Block Design tests and was interpreted as a Visual Segmentation Factor. The second received loadings from the Impossible-Possible Figures Test and the Navon Hierarchical Figures Test and was interpreted as a Visual Integration Factor. Higher level tasks such as identification of fragmented pictures, picture memory and drawing style 


\section{TABLE 2.}

A Summary of Reported Correlations and Extracted Factors in Tasks that Measure Perceptual Style

\begin{tabular}{ll}
\hline Study & Tests administered \\
\hline Booth, 2006 & \\
& $\begin{array}{l}\text { Lower-level tasks } \\
\text { Embedded Figures Test (EFT), Block Design } \\
\text { (BD), Impossible-Possible Figures Test (I-PFT) } \\
\text { Navon Hierarchical Figures (NHF) }\end{array}$ \\
& \\
& Higher-level tasks \\
& Fragmented Pictures (FP), Picture Memory: \\
& Description (PM:D), Picture Memory: \\
& Recognition (PM:R), Drawing Style (DS)
\end{tabular}

Burnette et al., 2005

Edgin \&

Pennington, 2005 Jarrold et al., 2005

Pellicano, Maybery, Durkin, \& Maley, $2006^{\mathrm{a}}$

Embedded Figures Test (EFT), Block Design (BD), Pattern Construction (PC)

Embedded Figures Test (EFT), Block Design (BD)

Children's Embedded Figures Test (CEFT),

Visual Feature Search (FS), Visual Conjunctive Search (CS)

Pre-school \& Children's Embedded Figures Tests (EFT), Pattern Construction (PC), FigureGround Test (F-G), Visual-Motor Integration (VMI)

Pellicano, Maybery, Pre-school Embedded Figures Test (PEFT), et al., 2005 Pattern Construction (PC), Figure-Ground Test (F-G), Visual-Motor Integration (VMI)

Ropar \& Mitchell, Children's Embedded Figures Test (CEFT), Block 2001

Study
Design (BD), Selection of illusions including Muller-Lyer (MLI) Tests administere Embedded Figures Test (EFT), Block Design (BD), Impossible-Possible Figures Test (I-PFT), Navon Hierarchical Figures (NHF)

Pellicano, Gibson, Pre-school Embedded Figures Test (PEFT), et al., 2005

Teunisse et al., 2001

Pattern Construction (PC), Figure-Ground Test (F-G), Visual-Motor Integration (VMI) Embedded Figures Test (EFT), Children's Embedded Figures Test (CEFT), Visual Object Spatial Perception-Silhouettes (VOSP-S), VOSPObject Decision (VOSP-OD), VOSP-Progressive Silhouettes (VOSP-PS), Spot the Differences (SD), Spatial Card Sorting Test (SCST), Wisconsin Card Sorting Test (WCST), Number Card Sorting Test (NCST), California Verbal Learning Test (CVLT), Switch In Series (SIS), Cambridge Neuropsychological Test Automated Battery (CANTAB)

Wasserstein, Barr, Mooney Faces (MF), Street Gestalt Completion Zappulla, \& Rock, 2004 (SUF), Gestalt Completion Test (GCT), Contour Illusion Test (CIT), Facial Recognition (FR)

Sample size Relationships

Pearson's $r$ coefficients

ASD

TD

$\mathrm{ASD}=31$
$\mathrm{TD}=204$

EFT \& BD
EFT \& I-PF

EFT \& NHF

BD \& I-PFT

BD \& NHF

NHF \& I-PFT

FP \& PM:D

FP \& PM:R

FP \& DS

PM:D \& PM:R

PM:D \& DS

PM:R \& DS

$\mathrm{ASD}=23$,

$\mathrm{TD}=20$

EFT \& PC

BD \& PC

EFT \& BD

$\mathrm{ASD}=24$,

$\mathrm{TD}=34$

$\mathrm{ASD}=18$,

$\mathrm{TD}=18$

$\mathrm{ASD}=40$,

$\mathrm{TD}=40$

$\mathrm{TD}=70$

.


were also administered, however these did not correlate with each other and were not entered into the factor analysis (see Booth, 2006).

Other authors have reported the strength of correlations between different tasks used to measure perceptual styles, although these correlations are often presented as secondary to the primary hypothesis of the research, which is usually aimed at comparing performance of a developmentally delayed group against a control group. Table 2 presents a summary of these findings. Most, although not all, of this work stems from the field of developmental disorders, specifically autism research, therefore the table specifies whether the data are collected from a clinical or a neuro-typical population.

In general these studies suggest a modest degree of correlation between different tasks purported to measure central coherence, but they do not provide evidence for a single factorial structure. Furthermore, the scope of the analyses was limited as each study typically included only a small subset of tasks.

Since the aim of the present study was to explore the factorial structure of many tasks that have been used to measure either central coherence, field-(in)dependence or global-local perceptual style, we reviewed the literature and identified 14 tasks that are employed for this purpose. Based on this literature review and speculative task analysis, we defined these tasks as measuring the following constructs:

1. The ability to dis-embed and detect a simple stimulus from embedding context (the Embedded Figures Test, the Hidden Patterns Test, and a newly developed Spot the Differences Test).

2. The ability to segment a $2 \mathrm{D}$ or $3 \mathrm{D}$ shape into individual elements (Block Design and the Copying Test).

3. The ability to detect targets within a non-embedding array (Visual Search).

Note that we made a conceptual distinction between the "embedded" tasks such as the Embedded Figures Test and the Hidden Patterns Test, where targets share contours and boundaries with the embedding context, and the Visual Search Test in which the target is a discrete entity positioned within an array of distractors.

4. The bias towards a more globally or more locally dominated perceptual style (the Navon Hierarchical Figures Test and copying strategy of the Rey-Osterrieth Complex Figure).

5. The ability to draw disparate information into a coherent whole (the Gestalt Completion Test, the Kanizsa task and the Good Form task). 6. The ability to integrate contiguous elements within a single stimulus (Impossible-Possible Figures Test and MullerLyer illusion).

7. Global perception without Gestalt demands, when target identification is based solely on the figure's global form (Silhouettes test from the Visual Object Spatial Perception Battery [VOSP]).

In addition, we measured participants' sensitivity to coherent motion and coherent form, as significant correlations between performance on the Children's Embedded Figures Test and coherent motion thresholds have been reported in children with autism (Pellicano, Gibson, Maybery, Durkin, \& Badcock, 2005), and detection of both coherent motion and coherent form can be seen as measures of low-level perceptual integration.

\section{METHOD}

\section{Participants}

Ninety participants, 49 females and 41 males, were recruited to the study via posters displayed on the university campus and an e-mail that was sent to a list of registered volunteers. All participants were students: 60 undergraduates, 7 MPhil students, and $23 \mathrm{PhD}$ students. The average age of the participants was 21 years and 3 months with a standard deviation of 3 years. The exclusion criteria were: speaking a language other than English as a first language and/or being older than 30 or younger than 18 . We recruited participants from a range of faculties across the university, the percentage of participants from each faculty was Arts, 21\%; Engineering, 14.4\%; Medicine, 9\%; Law, 7.8\%; Pure Science, 25.7\%; and Social Science, 20.7\%. Participants provided a history of any developmental disorder or existing condition that may affect their performance on the tasks (e.g., uncorrected visual impairment, motor problems, etc.). Four participants disclosed a diagnosis of dyslexia, one was red/green colour blind, and three reported having a lazy eye. These were noted in all cases but as they represent a cross section of the typical population were not considered grounds for exclusion from the study. ${ }^{1}$

\section{Experimental tasks: "Pen and Paper"}

THE GROUP EMBEDDED FIGURES TEST (WITKIN ET AL., 1971)

Participants were presented with a booklet of complex figures printed one to a page. Each complex figure had one simple target figure, out of a possible nine, embedded within it. Participants were asked to identify and trace around the simple figure embedded within each complex figure. The test consists of three parts the first of which is considered practice. Parts two and three each contained nine complex figures and had a time limit of $5 \mathrm{~min}$. The test was administered according to the instructions in the manual. The dependent variables were the number of embedded targets identified correctly in parts two and three, out of a possible 18, and the time taken to complete them, out of the total 5 min allowed.

\section{HIDDEN PATTERNS TEST (FROM THE EDUCATIONAL TESTING SERVICES KIT; EKSTROM, FRENCH, HARMAN, \& DERMAN, 1976 )}

Stimuli were line drawings of geometric patterns. Some of the patterns contained the embedded target configuration. Participants were required to mark, for each item, whether or not the target configuration occurred (see Figure 1). Following an untimed practise session of 10 stimuli, two parts of the test were given. In each part, participants were allowed $60 \mathrm{~s}$ to mark whether the target was present or absent in as many patterns as possible. The dependent variable was the number of correct responses given in both parts, out of a possible 200. 


\section{GESTALT COMPLETION TEST (FROM THE EDUCATIONAL TESTING SERVICES KIT; EKSTROM ET AL., 1976)}

Drawings composed of black patches representing parts of objects were presented and participants were asked to write down what each drawing depicted (see Figure 1). The experiment was presented in two parts. Following an un-timed practise session participants were given 120 seconds to identify as many objects as they could in each part. The dependent variable was the number of objects identified correctly in both parts, out of a possible 20 .

\section{COPYING TEST (FROM THE EDUCATIONAL TESTING SERVICES KIT; EKSTROM ET AL., 1976 )}

Each item of this task consisted of a four-line geometrical figure and a square matrix of dots presented in a $5 \times 5$ array. The task was to copy the figure exactly onto the matrix of dots (see Figure 1). Again this task was administered in two parts. Following an untimed practise session, participants were given $90 \mathrm{~s}$ to copy as many patterns as they could in each part. The dependent variable was the number of correctly copied figures, out of a possible 64 .

\section{VOSP-SILHOUETTES(WARRINGTON \& JAMES, 1991)}

The stimuli of this task were drawings of 30 objects presented as silhouettes. Each participant had unlimited time to identify each object. The dependent variable was the number of objects correctly identified, out of a possible 30 .

\section{SPOT THE DIFFERENCES TEST}

This was a traditional spot the difference puzzle adapted specifically for this study. The stimuli originally appeared in a pre-1990 edition of a Polish popular weekly magazine called Przekrój. These images were chosen as they were considered to be sufficiently challenging for adults and were highly unlikely to have been seen previously by any of the participants. Two versions were given: a kitchen scene and a fishing scene (see Figure 1). Each scene was presented as a black and white line drawing reproduced twice on one piece of A4 paper. The participant was informed that the two pictures differed in a number of small details, and were asked to mark any differences they detected by putting a cross in the appropriate place on the right-hand side image. A $60 \mathrm{~s}$ time limit was given for each picture. The differences could concern placement of features, size of features, number of clustered features, orientation of features, and addition/subtraction of features. The order of scene presentation (kitchen or fishing) was counterbalanced between participants. The dependent variable was the total number of differences detected, out of a possible 39 and 34 for the kitchen and fishing scenes, respectively.

\section{REY-OSTERRIETH COMPLEX FIGURE (REY FIGURE)}

Participants were presented with a laminated card showing the Rey figure (Osterrieth, 1944), given a blank piece of paper and a pencil, and asked to reproduce the figure. Following a break of 5 min during which they engaged in another, unrelated task, they were given a surprise recall test and asked to re-draw the figure on a new piece of paper from memory. Participants were filmed in both conditions. The copies were scored for accuracy and strategy, recall was scored for accuracy only. Accuracy was scored according to Osterrieth's (1944) criteria, adapted by Taylor (1959; reproduced in Lezak, Howieson, Loring, Hannay, \& Fischer, 2004, p. 542) which identifies 18 elements of the figure. Ambiguous cases were resolved using recommendations made by Strupczewska (1990), who further elaborated the Osterrieth's scoring criteria and provided examples. A maximum of 2 points was available for the reproduction of each element, giving a maximum possible score of 36 . Strategy was scored by adopting the criteria suggested by Shorr, Delis, and Massman (1992) who considered the Rey figure as an assembly of eight sub-components. For each sub-whole, junctures were identified where breaks in continuous drawing of the sub-wholes can occur. Participants received 1 point for every juncture that was completed by either continuous or contiguous lines, with a maximum possible of 20. A high score on this system therefore indicates a globally biased drawing style, whereas a low score indicates a more locally biased, piecemeal drawing style. The scoring system template is illustrated in Figure 1. In total, three dependent variables were obtained from this test: copy accuracy score, recall accuracy score, and strategy score.

\section{Experimental tasks - computerised}

The following computerised tasks were presented on a Viglen laptop computer, the screen of which was 1024 pixels wide $(285 \mathrm{~mm})$ and 768 pixels high $(215 \mathrm{~mm})$, which refreshed at $60 \mathrm{~Hz}$. The experiments were written and presented in either E-prime (Psychology Software Tools, Inc.; www.pstnet.com) or Visual Basic (Visual Studio 2005, www.microsoft.com). Luminance of the stimuli and background were measured with a Sekonic dual spot ( $1^{\circ}$ photometer) and Michelson contrast of the stimuli was calculated with the following formula $\left(L_{\max }-L_{\min }\right) /\left(L_{\max }+L_{\min }\right)$. The visual angle of the stimuli below is calculated based on an assumed distance of $47 \mathrm{~cm}$ from the computer screen.

\section{HIERARCHICAL FIGURES TEST (BASED ON NAVON, 1977) Stimuli}

Hierarchical stimuli consisted of large "global" letters composed of smaller "local" letters. Target stimuli were either "H" or "S" and neutral letters were " $\mathrm{X}$ ". The stimuli were compatible, neutral, or incompatible depending on the pairing of target and distractor stimuli and are detailed in Figure 2. All stimuli were black and were presented on a grey background (Michelson contrast $=76 \%$ ). The global outline of the stimuli subtended $3.66^{\circ} \times 4.87^{\circ}$.

\section{Design and procedure}

A selective attention design was used, whereby participants were instructed to indicate via a two-alternative choice key press whether the letter at the designated level was " $\mathrm{H}$ " or "S". A total of 144 trials were presented in 12 blocks. In half of the blocks the participant was instructed to identify the letter at the global level and in the other half the letter at the local level. Within each block the three different stimulus 
Hidden Patterns Test ${ }^{1}$ (fragment): Participants must indicate, underneath each stimulus, whether or not it contains the target (model). Time limit: $60 \mathrm{~s}$.

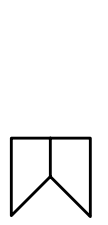

( )

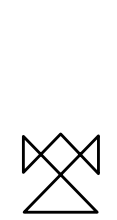

( )
Model:

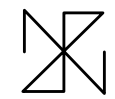

( )
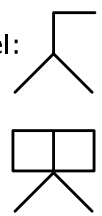

( )
Spot the Differences Test: Participants must detect as many differences between the two images as possible in $60 \mathrm{~s}$.

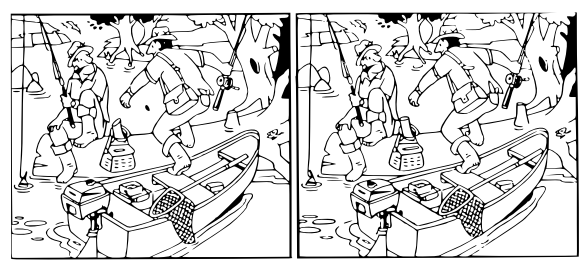

VOSP Silhouettes Test ${ }^{3:}$ Participants must identify as many items from their silhouette as possible (maximum $=30$, no time limit). Example below is a bicycle.

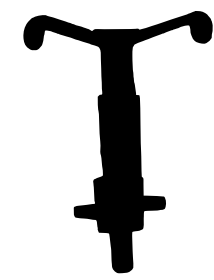

Group Embedded Figures Test ${ }^{4}$ : Participants must locate the target figure (right) embedded within the complex figures (maximum of 18). Time limit: $5 \mathrm{~min}$.

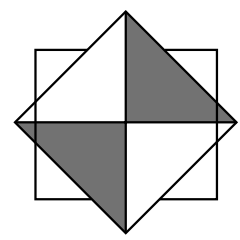

ROCF copying strategy scoring criteria ${ }^{2}$ : Each juncture (out of 20) crossed with a continuous or contiguous line scores 1 point. Note that this illustration contains only those elements of the figure that are relevant for scoring copying strategy.

\section{FIGURE 1.}

Examples of the stimuli used in the pen and paper tasks.

${ }^{1}$ Ekstrom, French, Harman, \& Derman (1976) Kit of Factor-Refrenced Cognitive Test (KIT) materials are reprinted by permission of Educational Testing Service, the copyright owner. However, the test questions and any other testing information is provided in their entirety by American Psychological Association. No endorsement of this publication by Educational Testing Service should be inferred. ${ }^{2}$ Adapted from Shorr, Delis, \& Massman (1992), from "Memory for the Rey-Osterrieth Figure: Perceptual Clustering, Encoding, and Storage", Neuropsychology, 6, 43-50. ${ }^{3}$ Reprinted from the Visual and Object Spatial Perception Battery, with permission from Harcourt Assessment. ${ }^{4}$ Reproduced by special permission of the Publisher, MIND GARDEN, Inc. (www.mindgarden.com) from the GROUP EMBEDDED FIGURES TEST by Herman A. Witkin, Philip K. Oltman, Evelyn Raskin, \& Stephen A. Karp. Copyright 1971, 2002 by Herman A. Witkin et al.. Further reproduction is prohibited without the Publisher's written con- 
types: compatible, neutral, or incompatible, and were presented randomly but equiprobably. To discourage the participant from looking at a fixed point on the screen where "local" letters always appeared, the stimulus appeared randomly either below or above a fixation point that remained on the screen for $500 \mathrm{~ms}$. Each stimulus stayed on the screen for $150 \mathrm{~ms}$, and was replaced by a pattern mask that remained until the participant made a response, following which the screen went blank for $500 \mathrm{~ms}$ before presentation of the next fixation point. Response time and accuracy were recorded.

\section{MULLER-LYER LINE LENGTH ILLUSION TASK Stimuli}

Six stimulus pairs were created. Each consisted of one horizontal line with illusion inducing fins placed above another parallel line without fins. The upper line with fins always subtended $7.3^{\circ}$. The lower line subtended either $7.3^{\circ}, 6.9^{\circ}$, or $7.7^{\circ}$; the length of the lower line was manipulated so that it was shorter than, longer than, or the same length as the upper line. The task was to indicate via a three-alternative choice key press whether the lower line was longer than, shorter than or the same length as the upper line. In three of the stimulus pairs the upper line had fins that pointed inwards and in the other three stimulus pairs the fins on the upper line pointed outwards. In the non-illusory condition, the lower line looked, and really was, either longer or shorter than the upper line with fins. In the illusory condition, the lower line was either longer or shorter than the upper line with fins but looked the same length as the upper line, or the lower line was the same length as the upper line with fins but looked either longer or shorter depending on the fins of the upper line. Examples of illusory (upper line) and nonillusory (lower line) are presented in Figure 2. The stimuli were black against a white background (Michelson contrast $=87 \%$ ).

\section{Design and procedure}

Each stimulus pair was presented eight times $(N=48$ trials $)$ in random order. Prior to stimulus presentation a central fixation cross appeared for $500 \mathrm{~ms}$. The stimulus remained on the screen until the participant made a response, following which the screen went blank for $500 \mathrm{~ms}$ before presentation of the next fixation cross. Response time and accuracy were recorded.

\section{KANIZSA ILLUSORY CONTOUR TASK (BASED ON RINGACH \& SHAPLEY, 1996) \\ Stimuli}

Stimuli were illusory rectangles induced by white "pac-man" figures presented on a black background. The dimensions of the stimuli were governed by the angle of pac-man rotation. In half of the images the pac-man figures were rotated to create the perception of a "fat" rectangle while in the other half they were rotated to create the perception of a "thin" rectangle. The degree of rotation was either $5^{\circ}, 10^{\circ}$, or $15^{\circ}$ from the horizontal midline, this resulted in a percept with varied degrees of "fatness" or "thinness". Participants were instructed to identify whether the shape was fat or thin via a two-alternative choice key press.
The images were presented at different orientations: straight, rotated $45^{\circ}$ to the left, or $45^{\circ}$ to the right to prevent any participant using a strategy of ascertaining the shape of the induced rectangle by looking at the angle of orientation of one inducer only. Each stimulus subtended $5.48^{\circ} \times 8.52^{\circ}$. Control, non-illusory stimuli were created that were identical to the illusory stimuli apart from white line contours (2 pixels wide) that were drawn to highlight the rectangle. Michelson contrast of the stimuli was $87 \%$.

\section{Design and procedure}

Two separate blocks of trials were administered: the illusory block and the control block. The order of block presentation was counterbalanced between participants. In each block, the six stimuli were presented nine times giving a total of 54 trials per block. Each stimulus was equally likely to be presented upright, oriented to the left, or oriented to the right. Prior to stimulus presentation a central fixation cross appeared for $500 \mathrm{~ms}$. The stimulus remained on the screen until the participant made a response, following which the screen went blank for $500 \mathrm{~ms}$ before presentation of the next fixation cross. Response time and accuracy were recorded.

\section{VISUAL SEARCH FOR A CONJUNCTIVE TARGET (BASED ON PLAISTED ET AL., 1998) \\ Stimuli}

The stimuli consisted of an array of letters in a virtual grid, from which participants were instructed to search for a target amidst distractors. The target was a red " $\mathrm{X}$ ", the distractors were red letters " $\mathrm{T}$ " and green letters "X". Each letter measured approximately $0.5^{\circ} \times 0.5^{\circ}$ and the virtual grid subtended $20.3^{\circ} \times 20.3^{\circ}$.

\section{Design and procedure}

Participants were instructed to press one of two keys to indicate whether the target was present or not. From a total of 60 trials, 30 contained the target. In each trial 5, 15, or 25 distractors were presented with equal probability but random selection. Prior to the array presentation, a fixation cross appeared on the screen for $500 \mathrm{~ms}$, and disappeared once the stimulus appeared. The stimulus remained on the screen until the participant made a response, following which the screen went blank for $500 \mathrm{~ms}$ before presentation of the next fixation cross. Response time and accuracy were recorded.

\section{IMPOSSIBLE-POSSIBLE FIGURES TEST}

Stimuli

The stimuli were figures used by von Karolyi, Winner, Gray, and Sherman (2003), and were adapted from the set of possible and impossible images developed by Schacter, Cooper, and Delany (1990). These were geometrically possible $(n=12)$ or impossible $(n=11)$ black line drawings presented on a white background (Michelson contrast $=87 \%$ ). Participants indicated via a two-alternative choice key press whether the presented stimulus was geometrically possible or impossible. Each stimulus subtended approximately $5.1^{\circ}$ x $5.5^{\circ}$. 


\section{Design and procedure}

Prior to the presentation of each figure, a fixation cross appeared on screen for $500 \mathrm{~ms}$. One of the 23 figures then appeared at random and remained on the screen until a response was made, following which the screen went blank for $500 \mathrm{~ms}$ before the reappearance of the fixation cross. Response time and accuracy were recorded.

\section{GOOD FORM TASK (ADAPTED FROM WILLIAMS \& BOLOGNA, 1985)}

Stimuli

"Good form" experimental stimuli were pairs of vertical brackets that were designed to elicit perceptual closure. "Poor form" control stimuli were horizontal and vertical brackets that did not elicit perceptual closure (see Figure 2). In each block participants were instructed to sort the stimuli into two groups (arbitrarily classified as left or right) via a two-alternative choice key press. Theoretically this task could be successfully completed by selectively attending to the right bracket of each pair only. The experimental images subtended $1.2^{\circ} \times 1.8^{\circ}$, the control images subtended $3.65^{\circ} \times 1.8^{\circ}$.

\section{Design and procedure}

In each trial, one bracket pair appeared on the screen; 144 trials were organised into two conditions (experimental good form and control poor form) and six separate blocks. Four out of six blocks were defined as "simple" as only one stimulus pair was associated with each response. In the simple blocks the irrelevant (left) bracket was predictable, that is it always faced the same way. The other two blocks were defined as "orthogonal" as two stimulus pairs were associated with each response. In these blocks the irrelevant left bracket was unpredictable, in other words, it could face either direction. Williams and Bologna (1985) found that reaction time to classify the stimuli was significantly longer in the orthogonal experimental blocks than in the simple experimental blocks or any control blocks. They interpreted this as a result of perceptual grouping, that is the greater the tendency for perceptual grouping the harder it was to selectively attend to the relevant right bracket (and ignore the irrelevant left) to the detriment of performance. Since the aim of this task was to test the drive for perceptual grouping rather than memory, visible prompts were available at all times to remind participants which stimulus pairs were associated with which response. The order of block administration was counterbalanced across participants. After instruction, a fixation cross appeared on the screen for $500 \mathrm{~ms}$, this was replaced by the stimulus which remained on the screen until a response was made, following which, the screen went blank for $500 \mathrm{~ms}$ before presentation of the next stimulus. Response time and accuracy were recorded.

\section{Additional psychometric variables CHOICE RT}

As most of the experimental tasks administered above required participants to make an alternative choice by pressing one of two keys as quickly as possible, this control task provided a baseline measure of choice reaction time.

\section{Stimuli}

The stimuli were red and blue circles with a diameter of $5.36^{\circ}$. They appeared in the centre of the computer screen against a white background (Michelson contrast $=58 \%$ and $52 \%$, respectively).

\section{Design and procedure}

The circles were presented in random order. Participants were instructed to indicate the colour of the stimulus via a two-alternative choice key press. Prior to the presentation of each stimulus a fixation cross appeared on the screen for $500 \mathrm{~ms}$, the stimulus then appeared and remained until a response had been made, after which the screen went blank for $500 \mathrm{~ms}$ before the reappearance of the fixation cross. Each participant completed 32 trials. Response times and accuracy were recorded.

\section{MOTION COHERENCE THRESHOLD (HANSEN, STEIN, ORDE, WINTER, \& TALCOTT, 2001)}

A standard random dot kinematogram (RDK) stimulus was used, consisting of two horizontally adjacent panels of moving dots. Each contained 300 white dots (1 pixel) of high contrast (approx. 90\%) against a black background. Each panel was rectangular, subtending $10^{\circ} \times 14^{\circ}$ and separated horizontally by $5^{\circ}$. One panel contained a variable proportion of target dots that moved coherently to the left and right over successive screen refreshes, whilst the remaining noise dots in the panel moved with the same speed but in a direction that randomly changed between refreshes. The other panel contained only noise dots. To prevent tracking of individual dots, the lifetime for each dot was fixed at three animation frames $(85 \mathrm{~ms})$ after which time the dot was regenerated at a random position inside the same panel.

\section{FORM COHERENCE THRESHOLD (HANSEN, STEIN, ORDE, WINTER, \& TALCOTT, 2001)}

Two rectangular panels were presented side by side, matched in size and overall luminance to the motion task. Each panel consisted of 600 short, high contrast line elements, with each element being $0.4^{\circ}$ in length. In one panel there was a coherent form signal, defined by line elements that were oriented tangentially to imaginary concentric circles within an area of $8^{\circ}$ diameter. Signal coherence was varied by modifying the percentage of aligned elements. At 100\% coherence therefore, all line elements within the $8^{\circ}$ boundary would be perfectly aligned. Elements outside the $8^{\circ}$ area were orientated randomly. In the other panel, all elements were randomly orientated.

In both the motion and form coherence tasks participants were asked to identify the patch that contained the coherent signal via two alternative forced choice key press. Auditory feedback was given after each trial. Three sets of trials in each task were administered. The final threshold for each task was calculated as the average threshold of the three sets of trials. Signal coherence was varied by modifying the number of coherent elements within the target patch. Each set of trials started with signal at $75 \%$ coherence. Following a correct response, coherence decreased by $1.5 \mathrm{~dB}$ and following an incorrect response coherence increased by $0.5 \mathrm{~dB}$ (Kaernbach, 1991). Each set was terminated after 
Good Form task: One pair of brackets is presented at a time. The participant must map the brackets to a response with either the right or left key.

Experimental ("good form") trials Control trials

\begin{tabular}{|c|c|c|c|c|}
\hline Simple condition 1 & $(($ & ( ) & $(\smile$ & $(\frown$ \\
\hline Simple condition 2 & )( & ) ) & ) $\smile$ & )$\frown$ \\
\hline Mixed condition & ( & ( ) & $(\underset{\text { or }}{\smile}$ & or \\
\hline & )( & ）） & ) $\smile$ & )$\frown$ \\
\hline
\end{tabular}

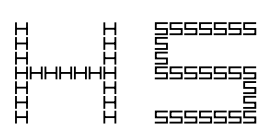

Compatible

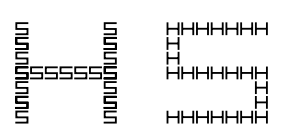

Incompatible

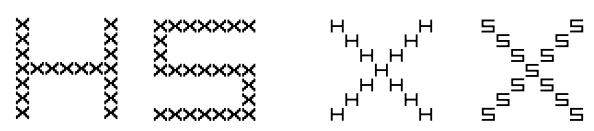

Neutral (global blocks) Neutral (local blocks)
Muller-Lyer task: One set of line pairs appears at a time and participants indicate whether the line without fins is longer than, shorter than, or the same length as the line above with fins. The top pair are illusory whereas the bottom pair are not.
Navon Hierarchical Figures Test: One figure appears at a time and participants indicate which letter ( $\mathrm{H}$ or $\mathrm{S}$ ) appears at the target level (global or local). Stimuli can be compatible, incompatible, or neutral.
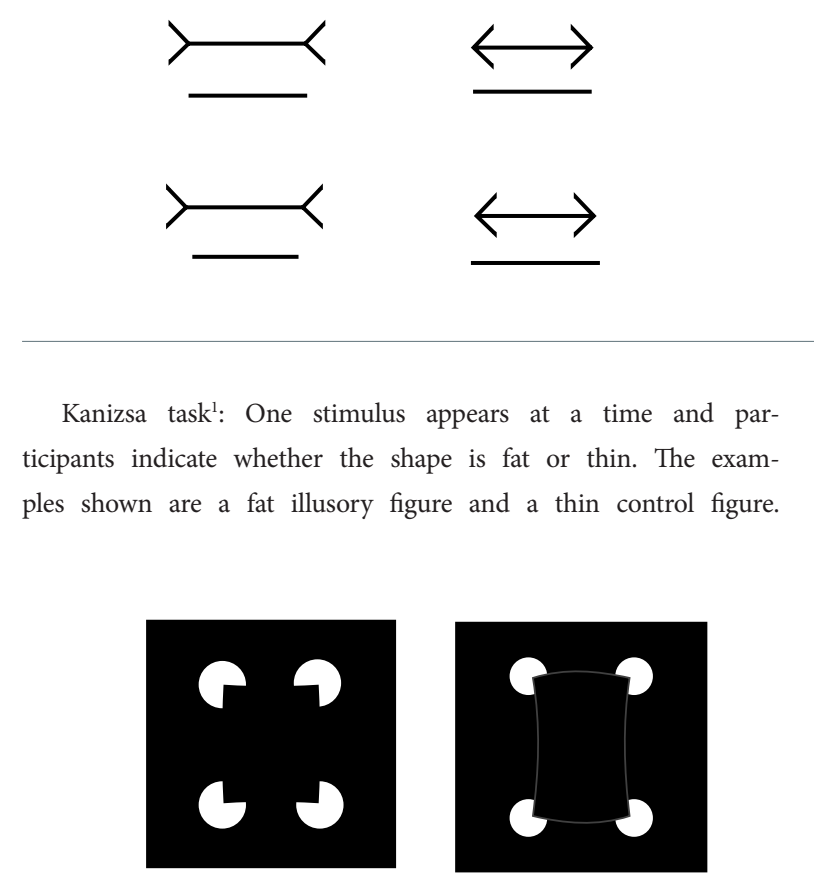

Visual Search task: The image depicts one possible stimulus array. The participant indicates whether the target (red X) is present or absent.

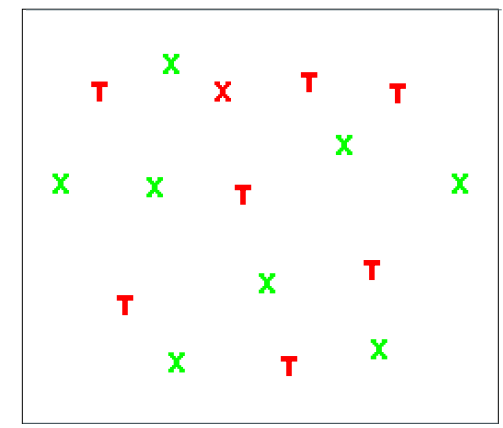

Possible Impossible Figures Test: One figure appears at a time and participants indicate whether the shape is physically possible or impossible (one of each shown).
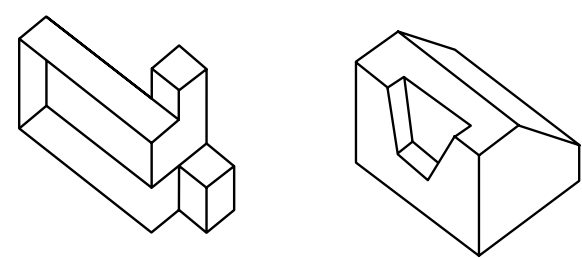

\section{FIGURE 2.}

Examples of the stimuli used in the computer tasks.

${ }^{1}$ Reproduced with permission from The British Journal of Developmental Psychology @ The British Psychological Society. 
10 reversals. Threshold within each set was calculated as the geometric mean of the last 8 reversal points. The order of presentation of form and motion coherence tasks was counterbalanced between participants.

\section{GENERAL INTELLECTUAL ABILITY}

IQ was assessed with the Wechsler Abbreviated Scales of Intelligence (WASI; Wechsler, 1999). This consists of four subtests: two verbal (Vocabulary and Similarities) and two performance (Block Design and Matrix Reasoning).The tasks were administered according to the manual. As the Block Design subtest is also an index of perceptual styles this was included as one of the experimental variables and IQ was derived from two subtests only (Vocabulary and Matrix Reasoning), using norms provided in the test manual.

\section{General procedure}

The study received ethical approval from university ethics sub-committees. All participants provided informed consent before taking part and received $£ 10$ for their participation. The tasks were administered during two sessions (at least one day apart) that lasted approximately 2 hours each. Four different schedules counterbalanced the order of task administration. Three participants did not return for the second session.

\section{RESULTS}

\section{Preliminary analysis}

Descriptive statistics for all tasks are presented in Appendix A. In order to establish whether the tasks used in this study produced within-task patterns of results that were consistent with those reported in published studies, preliminary analyses were carried out and are reported in Appendix B. In all cases median response times based on correct responses only are reported and analysed. There were some missing data points for some variables (reflected in the varying degrees of freedom). All of the tasks showed the expected pattern of results based on previously published studies (see Appendix B).

\section{Selection of tasks for correlation and factor analyses}

The following tasks were selected for factor analyses: (a) Block Design raw score, (b) Group Embedded Figures Test (accuracy and completion time), (c) Copying Test accuracy, (d) Gestalt Completion Test accuracy, (e) VOSP-Silhouettes accuracy, (f) Spot the Differences Test accuracy, (g) Rey figure copying strategy, (h) Impossible-Possible Figures Test (median RT [reaction time] to classify the impossible figures), (i) Navon Hierarchical Figures Test (accuracy and median RT to correctly identify incompatible targets separately at the global and local level), (j) Muller-Lyer (number of illusions correctly identified and median RT to correctly identify them), (k) Kanizsa (number of shapes defined by illusory contours correctly identified and median RT to identify them; Kanizsa, 1974), (1) Visual Search Task (number of targets detected during visual search amongst 25 distractors and median RT to detect them), and (m) Good Form Task (the experimental orthogonal condition, median RT to correctly classify the brackets). These tasks, or parts of tasks, were included because they tap most directly into the constructs of global and local processing under investigation.

The following tasks or conditions were excluded because they were considered to be control tasks and as such did not tap global/ local perception directly: (a) Rey Figure accuracy of copy and recall, the possible figures (control) condition of the Impossible-Possible Figures Test; (b) Navon Hierarchical Figures accuracy and RT in the compatible and neutral conditions; (c) Muller-Lyer non-illusory condition; (d) Kanizsa non-illusory condition; (e) Visual Search Task 5 and 15 distractors conditions; (f) all control conditions and experimental simple conditions of the Good Form Task. Accuracy scores the Impossible-Possible Figures and Good Form tasks were also excluded as most participants obtained ceiling scores. Additional variables - IQ (as measured by WASI), choice RT, and Form and Motion Coherence thresholds - were not entered into factor analyses, but used in correlation analyses (reported below).

\section{Reliability analyses}

Indices of reliability were computed for all measures entered into correlation and factor analyses, with the exception of the WASI IQ variables whose psychometric properties are well described in the literature. Measures of split-half, parallel test, and internal consistency reliability were computed, as appropriate. For the Rey figure copying strategy, two indices were obtained: internal consistency (based on data from all participants, scored and agreed jointly by both authors) and inter-rater reliability (using data from 30 participants, scored independently by a person who was blind to the authors' scores). The results are presented in Table 3.

The reliability of the tests varied considerably. The tests with relatively low reliability (below .70) were typically the measures of accuracy rather than response time. The lowest reliabilities (below .50) were obtained for Visual Search accuracy, Gestalt Completion Test accuracy, and Navon Hierarchical Figures Test accuracy in the global incompatible condition. This may result from the fact that two of the tests were relatively easy (Visual Search and Navon global incompatible condition, see Appendix A), and two of them (Visual Search and Gestalt Completion Test) were relatively short.

\section{Relationships between tasks DATA PREPARATION}

Some data points were missing due to equipment failure, administrators' errors, or participants' failure to attend one of the assessment sessions. For most variables one to four data points were missing, which constituted $1.1-4.4 \%$ of potentially available data. The only exceptions were Rey figure strategy and Visual Search (accuracy and reaction time) with $15(16.7 \%)$ and 9 (10\%) data points missing, respectively. The missing data points were replaced using expectation maximization (EM) method (Tabachnick \& Fidell, 2001). The EM procedure included all cognitive variables and WASI raw scores. Little's MCAR test was carried out on all variables and was not significant $\left(\chi^{2}\right.$ 


\section{TABLE 3.}

Reliability of the Measures Used in the Study

\begin{tabular}{|c|c|c|}
\hline Task & Reliability & Reliability index \\
\hline \multicolumn{3}{|l|}{ Group Embedded Figures Test } \\
\hline $\mathrm{RT}$ & .568 & Equal length Spearman-Brown \\
\hline \multirow{2}{*}{\multicolumn{3}{|c|}{ Hidden Patterns Test }} \\
\hline & & \\
\hline \multicolumn{2}{|l|}{ Gestalt Completion Test } & Equal length Spearman-Brown \\
\hline $\begin{array}{l}\text { Accuracy } \\
\text { Copying Test }\end{array}$ & .422 & Equal length Spearman-Brown \\
\hline $\begin{array}{c}\text { Accuracy } \\
\text { VOSP-Silhouettes }\end{array}$ & VOSP-Silhouettes & Equal length Spearman-Brown \\
\hline \multicolumn{3}{|l|}{ Spot the Differences Test } \\
\hline $\begin{array}{l}\text { Accuracy } \\
\text { Rey figure }\end{array}$ & Rey figure & Equal length Spearman-Brown \\
\hline Copying strategy: Internal consistency & .850 & Cronbach's alpha \\
\hline Copying strategy: Inter-rater reliability & .962 & Intraclass correlation \\
\hline \multicolumn{3}{|c|}{ Navon Hierarchical Figures Test, incompatible condition } \\
\hline Global RT & .937 & Equal length Spearman-Brown \\
\hline Global accuracy & .459 & Equal length Spearman-Brown \\
\hline Local RT & .858 & Equal length Spearman-Brown \\
\hline \multicolumn{3}{|l|}{$\begin{array}{l}\text { Local accuracy } \\
\text { Muller-Lyer illusory condition }\end{array}$} \\
\hline RT & .950 & Equal length Spearman-Brown \\
\hline Accuracy & .767 & Equal length Spearman-Brown \\
\hline \multicolumn{3}{|l|}{ Kanizsa illusory condition } \\
\hline $\mathrm{RT}$ & .931 & Equal length Spearman-Brown \\
\hline Accuracy & .784 & Equal length Spearman-Brown \\
\hline \multicolumn{3}{|c|}{ Visual Search, target present amongst 25 distractors } \\
\hline RT & .855 & Equal length Spearman-Brown \\
\hline Impossible-Possible Figures Test & .153 & Equal length Spearman-Brown \\
\hline $\begin{array}{l}\text { Impossible-Possible Figures lest } \\
\text { RT } \\
\text { Good Form task experimental orthogonal t }\end{array}$ & .909 & Equal length Spearman-Brown \\
\hline $\begin{array}{l}\text { RT } \\
\text { Choice RT }\end{array}$ & .925 & Equal length Spearman-Brown \\
\hline RT & .909 & Equal length Spearman-Brown \\
\hline Motion coherence (\% threshold) & .818 & Cronbach's alpha \\
\hline Form coherence ( $\%$ threshold) & .567 & Cronbach's alpha \\
\hline
\end{tabular}

$=445.724, d f=452, p=.574)$ indicating that data can be assumed to be missing at random.

All variables that were entered into correlation and factor analyses were winsorised for outliers: All scores that were more than 2.33 standard deviations away from the mean (which, under normal distribution, corresponds to the top and bottom $1 \%$ of cases) were set to the value of 2.34 standard deviation away from the mean. After this treatment, no variables showed extreme departures from normality (defined as the absolute value skewness greater than 2 and/or the absolute value of kurtosis greater than 7; West, Finch, \& Curran, 1995, as cited in Fabrigar, Maccallum, Wegener, \& Strahan, 1999). The largest skewness (1.46) was observed on the Impossible Figures RT data, and the largest kurtosis (1.91) on Kanizsa accuracy.

\section{CORRELATION ANALYSIS}

Table 4 reports zero-order and partial correlations, controlling for estimated full scale IQ based on two subtests from the WASI, and choice RT, for all variables. It is apparent that the significant correlations appear mostly between non-computerised tasks. Also, the differences between zero-order and partial correlations are mostly negligible, suggesting the relationships between variables in the study are not mediated by general cognitive ability or choice reaction time.

\section{FACTOR ANALYSES}

The factor analyses reported below used the Alpha Factoring method of factor extraction. This method was chosen because it "considers the variables in the analysis to be a sample from the universe of potential variables" (SPSS, 2005). This was appropriate in our case, the "universe" being all potential variables measuring perceptual style. Alpha factoring also maximises the reliability (internal consistency) of the extracted factors. This results in a conservative estimate of the proportion of total variance explained by the latent factors. Factors were rotated using the Direct Oblimin method. 
TABLE 4. Correlations Between the Variables

\begin{tabular}{|c|c|c|c|c|c|c|c|c|c|c|c|c|c|c|c|c|c|c|c|c|c|c|}
\hline $\begin{array}{l}\text { WASI IQ } \\
\text { (2 subtests) }\end{array}$ & ' & ' & & ' & & ' & & ' & ' & ' & & & & ' & ' & ' & ' & ' & & ' & & ' \\
\hline Choice RT & ' & ' & 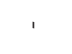 & ' & & ' & ' & ' & ' & ' & & ' & & ' & ' & ' & 1 & ' & & ' & & , \\
\hline $\begin{array}{l}\text { Form } \\
\text { Coherence }\end{array}$ & $\stackrel{\star}{\stackrel{n}{?}}$ & $\stackrel{\star}{\stackrel{*}{n}}$ & 8 & 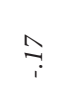 & $\stackrel{0}{\circ}$ & 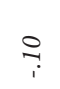 & $\Delta_{i}$ & $\stackrel{\infty}{\rightarrow}$ & 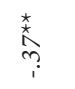 & $\tilde{i}$ & $\stackrel{20}{7}$ & $\stackrel{\star}{\stackrel{\star}{\imath}}$ & $\stackrel{\infty}{?}$ & $\stackrel{m}{7}$ & $S_{i}^{+}$ & $\stackrel{m}{7}$ & 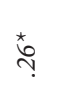 & 7 & $\cong$ & $\cong$ & $\stackrel{?}{-}$ & $?$ \\
\hline $\begin{array}{l}\text { Motion } \\
\text { Coherence }\end{array}$ & 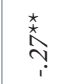 & $\stackrel{\infty}{\rightarrow}$ & 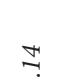 & 8 & $\overline{0}$ & $\stackrel{7}{7}$ & 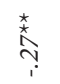 & $\underset{i}{i}$ & $\bar{c}$ & $\underset{i}{+}$ & $\hat{o}_{i}$ & $\stackrel{\star}{\stackrel{\imath}{i}}$ & $\overline{0}$ & oे & $\tilde{O}_{i}$ & 7 & $\bar{c}$ & $\stackrel{*}{*}$ & $\bar{c}$ & $\approx$ & 8 & \\
\hline $\begin{array}{l}\text { Good Form } \\
\text { RT }\end{array}$ & 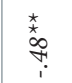 & $\stackrel{\star}{\stackrel{n}{?}}$ & 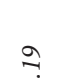 & $\stackrel{20}{7}$ & $\stackrel{7}{7}$ & 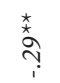 & $\stackrel{\Upsilon}{i}$ & $\stackrel{7}{7}$ & $\stackrel{\star}{\underset{1}{1}}$ & $\ell_{i}$ & $?$ & 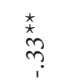 & $\stackrel{\infty}{=}$ & ț & $\stackrel{\frac{k}{x}}{m !}$ & $\%$ & $\stackrel{\star x}{\stackrel{*}{?}}$ & ? & $?$ & $\stackrel{?}{?}$ & & $\vec{i}_{i}$ \\
\hline $\begin{array}{l}\text { Impossible. } \\
\text { Figures RT }\end{array}$ & 8 & $\stackrel{2}{?}$ & o & $\stackrel{8}{0}$ & $\hat{o}$ & $\underset{i}{\infty}$ & $\stackrel{\#}{i}$ & $?$ & $\tilde{c}$ & $\stackrel{\star}{*}$ & 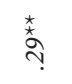 & gे & $\stackrel{\star}{\stackrel{\star}{~}}$ & ชุ. & $\stackrel{\star}{*}$ & $\infty$ & $\overbrace{i}$ & $\stackrel{?}{?}$ & $\infty$ & , & $\stackrel{\infty}{\longrightarrow}$ & $\stackrel{ }{\circ}$ \\
\hline $\begin{array}{l}\text { Visual Search } \\
\text { RT }\end{array}$ & 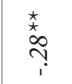 & $\stackrel{m}{7}$ & $\stackrel{\circ}{?}$ & $\stackrel{\star \star ⿱ 亠 乂}{\stackrel{m}{i}}$ & $\underset{i}{+}$ & $\stackrel{m}{7}$ & $\underset{T}{\sharp}$ & $\stackrel{7}{\because}$ & $\stackrel{\infty}{\infty}$ & $\stackrel{8}{i}$ & 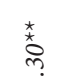 & ণุ & $\hat{o}$ & $\stackrel{m}{7}$ & $\stackrel{*}{*}$ & $\stackrel{m}{7}$ & $\stackrel{?}{?}$ & $\tilde{s}_{i}$ & & ọ. & $\exists$ & $\vec{\sigma}_{i}$ \\
\hline $\begin{array}{l}\text { Visual Search } \\
\text { acc. }\end{array}$ & $?$ & $\hat{o}$ & $\stackrel{0}{0}$ & ô & $\tilde{o}$ & ণุ & $\stackrel{?}{0}$ & $\stackrel{?}{-}$ & ș & $\stackrel{2}{-}$ & $?$ & 8 & $\stackrel{m}{\longrightarrow}$ & 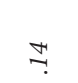 & $\stackrel{\star}{\stackrel{\star}{ָ}}$ & $\stackrel{\star}{\stackrel{\star}{~}}$ & $\hat{o}$ & , & $\tilde{\rho}_{i}$ & 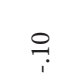 & $\stackrel{0}{0}$ & $\stackrel{\star}{\stackrel{*}{0}}$ \\
\hline Kanizsa RT & $\stackrel{\infty}{\circ}$ & $\hat{o}_{i}$ & $\because$ & 7 & $\tilde{r}_{i}$ & $\underset{i}{0}$ & $\cong$ & $\stackrel{\infty}{\rightarrow}$ & $\tilde{i}_{i}$ & $\delta_{i}$ & ò. & $\tilde{s}_{i}$ & $\infty$ & ? & $\stackrel{\star}{\stackrel{\star}{N}}$ & $\stackrel{7}{7}$ & , & $\stackrel{8}{0}$ & $\vec{\sim}$ & $\overrightarrow{c_{i}}$ & $\stackrel{\frac{x}{\star}}{m}$ & $\tilde{o}_{i}$ \\
\hline Kanizsa acc. & $\stackrel{\star}{\stackrel{\star}{\dagger}}$ & 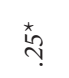 & $\stackrel{?}{i}$ & ô. & $\stackrel{0}{-}$ & $\simeq$ & $\infty$ & 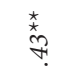 & $z_{i}^{2}$ & $\stackrel{\star}{\stackrel{\star}{y}}$ & 8 & $\approx$ & ò & 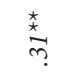 & $\stackrel{\star}{\stackrel{\star}{n}}$ & , & $\stackrel{\star}{\stackrel{\star}{i}}$ & $\stackrel{\star}{\text { స̦ }}$ & $\stackrel{20}{?}$ & $\stackrel{\infty}{\circ}$ & $\tilde{o}$ & $\stackrel{\circ}{\rightarrow}$ \\
\hline $\begin{array}{l}\text { Muller-Lyer } \\
\text { RT }\end{array}$ & $\underset{i}{\sharp}$ & $\tilde{o}_{i}$ & $=$ & $\stackrel{\star}{\stackrel{\star}{\imath}}$ & 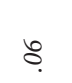 & $\hat{\text { ô }}$ & $\stackrel{?}{?}$ & $\underset{\longrightarrow}{\longrightarrow}$ & $\underset{i}{\not}$ & oे & 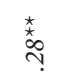 & $\because$ & 索 & $\stackrel{2}{\longrightarrow}$ & , & $\stackrel{\star t}{\stackrel{t}{0}}$ & กุ & $\stackrel{\star}{\stackrel{\star}{n}}$ & $\stackrel{\star \star ⿱ 亠 乂}{m}$ & $\stackrel{\star}{*}$ & 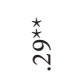 & $\overbrace{i}$ \\
\hline $\begin{array}{l}\text { Muller-Lyer } \\
\text { acc. }\end{array}$ & $\because$ & ণุ & $\underset{i}{*}$ & $\stackrel{\star}{\stackrel{*}{\dagger}}$ & $\stackrel{\star}{\dddot{\imath}}$ & $\stackrel{m}{\longrightarrow}$ & $\stackrel{?}{?}$ & $=$ & $\tilde{c}$ & $\tilde{o}_{i}$ & $\stackrel{8}{0}$ & $\cong$ & $\overbrace{i}^{0}$ & , & $\vec{\sim}$ & $\stackrel{\star \star ⿱ 亠 乂}{\stackrel{m}{m}}$ & $\tilde{c}$ & 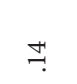 & $\stackrel{n}{i}$ & ฮุ. & ฮุ. & $\stackrel{\infty}{\stackrel{\rho}{i}}$ \\
\hline $\begin{array}{l}\text { Navon Local } \\
\text { RT }\end{array}$ & $\tilde{o}_{i}$ & $\tilde{s}_{i}$ & $\stackrel{\infty}{\longrightarrow}$ & 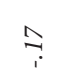 & $\tilde{o}_{i}$ & $\sigma_{i}$ & $\tilde{\beta}_{i}$ & ? & $\stackrel{\star}{\stackrel{\star}{~}}$ & $\begin{array}{l}\text { ta } \\
b \\
?\end{array}$ & 齐 & $\stackrel{m}{7}$ & & $g_{i}$ & $\stackrel{\star \star ⿱}{\star}$ & $\stackrel{n}{\circ}$ & $\stackrel{\infty}{\longrightarrow}$ & $\simeq$ & $\because$ & 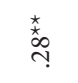 & 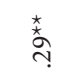 & $\varrho_{i}$ \\
\hline $\begin{array}{l}\text { Navon Local } \\
\text { acc. }\end{array}$ & $\stackrel{x}{*}$ & $\stackrel{\star \star ⿱ \star 乂}{\grave{\dagger}}$ & 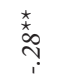 & $\stackrel{0}{\longrightarrow}$ & 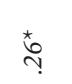 & 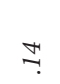 & ণิ & $\stackrel{\star}{\stackrel{\star}{~}}$ & $\stackrel{\star}{\stackrel{\star}{\Upsilon}}$ & $\stackrel{m}{\longrightarrow}$ & $\stackrel{\infty}{-}$ & 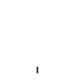 & $\overrightarrow{7}_{i}$ & $\stackrel{\infty}{\longrightarrow}$ & ọ $_{i}$ & 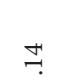 & $\tilde{o}_{i}$ & 눙. & ঙ্̣ & $\stackrel{ }{\circ}$ & 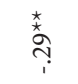 & $\stackrel{*}{\stackrel{*}{i}}$ \\
\hline $\begin{array}{l}\text { Navon Global } \\
\text { RT }\end{array}$ & $\underset{i}{0}$ & $\stackrel{n}{2}$ & $\stackrel{\infty}{\longrightarrow}$ & $\stackrel{\star}{\stackrel{\star}{i}}$ & $\underset{i}{0}$ & ș & $\stackrel{12}{7}$ & $\stackrel{\varphi}{0}$ & gे & $\stackrel{\star}{\stackrel{\star}{~}}$ & & $\cong$ & 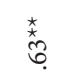 & $\stackrel{?}{\because}$ & $\stackrel{\star}{\stackrel{\overbrace{}}{?}}$ & $\stackrel{n}{n_{0}}$ & 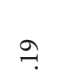 & $\stackrel{\infty}{\circ}$ & 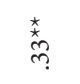 & 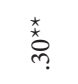 & ঙ̣ & $\stackrel{?}{?}$ \\
\hline $\begin{array}{l}\text { Navon Global } \\
\text { acc. }\end{array}$ & $\because$ & 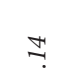 & $\bar{c}$ & $\stackrel{?}{?}$ & $\stackrel{?}{?}$ & ธุ. & $\bar{\sigma}$ & $\stackrel{\star}{\text { }}$ & $\stackrel{2}{\sim}$ & , & $\stackrel{\star}{\stackrel{\star}{\sim}}$ & $\dddot{?}$ & 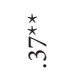 & $\dot{s}$ & $\stackrel{\infty}{0}$ & $\stackrel{\star}{\stackrel{\star}{\sim}}$ & $\tilde{o}_{i}$ & $\stackrel{10}{\sim}$ & $\underset{i}{H}$ & $\stackrel{\star}{\stackrel{\star}{~}}$ & $\tilde{c}_{i}$ & $\stackrel{n}{2}$ \\
\hline $\begin{array}{l}\text { Rey figure } \\
\text { Strategy }\end{array}$ & $\begin{array}{l}\stackrel{*}{\star} \\
\stackrel{n}{n} \\
m\end{array}$ & $\stackrel{\star}{ָ}$ & $\underset{i}{+}$ & $\approx$ & $\stackrel{\star}{خ}$ & oे & $\stackrel{\star}{\stackrel{\star}{ָ}}$ & $?$ & , & 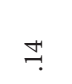 & 눙. & $\stackrel{\star}{ָ}$ & $\stackrel{0}{\longrightarrow}$ & ot. & $\&_{i}$ & $\hat{\theta}_{i}$ & $t_{i}$ & $\tilde{o}$ & ọ. & $\vec{i}$ & $\stackrel{\star}{\stackrel{*}{i}}$ & $\tilde{o}$ \\
\hline $\begin{array}{l}\text { Spot the } \\
\text { Differences }\end{array}$ & $\stackrel{\star \star ⿱ 亠 乂}{\stackrel{7}{*}}$ & $\stackrel{t}{t}$ & 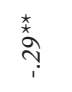 & ণ̣ & $\stackrel{\star}{\grave{N}}$ & $\stackrel{\star}{\stackrel{\star}{پ}}$ & $\stackrel{\infty}{\longrightarrow}$ & , & 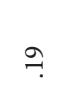 & $\stackrel{\star}{\stackrel{\star}{0}}$ & $\tilde{o}$ & $\stackrel{\star}{\sim}$ & ọ. & $\exists$ & $\exists$ & 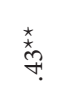 & ণ্ & $\cong$ & $F_{i}$ & $\stackrel{\infty}{\longrightarrow}$ & $\stackrel{7}{7}$ & $\stackrel{m}{\longrightarrow}$ \\
\hline Silhouettes & 䒺 & $\cong$ & $\stackrel{\infty}{\rightarrow}$ & $\stackrel{2}{-1}$ & 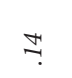 & $?$ & & $\stackrel{\infty}{\rightarrow}$ & $\stackrel{\infty}{\rightarrow}$ & ọ & $\underset{i}{\stackrel{7}{7}}$ & $\stackrel{\star}{\sim}$ & ọ. & gे & $\underset{7}{7}$ & $\stackrel{m}{\longrightarrow}$ & 7 & tọ. & $\stackrel{20}{i}$ & $F_{i}$ & $\stackrel{?}{?}$ & 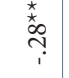 \\
\hline Copying & 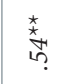 & $\stackrel{\star}{\star}$ & $\stackrel{\substack{* \\
6}}{?}$ & 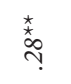 & $\stackrel{\star}{\stackrel{*}{n}}$ & 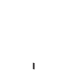 & $\stackrel{\infty}{\longrightarrow}$ & $\stackrel{\star \star N}{\stackrel{*}{\sim}}$ & $\stackrel{\infty}{0}$ & ọ & $\hat{o}$ & $\stackrel{m}{\hookrightarrow}$ & $\overrightarrow{\rho_{i}}$ & 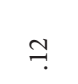 & $\hat{o}_{i}$ & 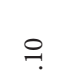 & o & ণุ̣ & $\exists$ & $\stackrel{\infty}{\stackrel{\infty}{i}}$ & $\stackrel{*}{\stackrel{*}{n}}$ & 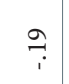 \\
\hline $\begin{array}{l}\text { Gestalt } \\
\text { Completion }\end{array}$ & 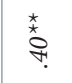 & $\hat{o}$ & $\stackrel{\star}{\stackrel{*}{\varphi}}$ & 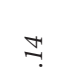 & & $\stackrel{\star}{\stackrel{*}{\sharp}}$ & 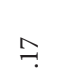 & $\stackrel{\star}{\stackrel{\star}{\oplus}}$ & 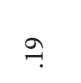 & $\stackrel{0}{-1}$ & $\dot{b}_{i}$ & $\stackrel{\star}{\stackrel{\star}{~}}$ & $\dot{S}_{i}$ & $\stackrel{\star}{\stackrel{\star}{n}}$ & $\stackrel{\infty}{\circ}$ & 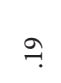 & $\ell_{i}$ & $\tilde{\sigma}$ & $\underset{i}{0}$ & $\hat{\circ}$ & $\stackrel{0}{\longrightarrow}$ & $\vec{\sigma}$ \\
\hline $\begin{array}{l}\text { Hidden } \\
\text { Patterns }\end{array}$ & م̣ & 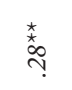 & $\stackrel{\star}{\star}$ & & $\stackrel{0}{-1}$ & $\stackrel{\star}{\triangleq}$ & $\stackrel{\infty}{!}$ & ণฺ & $=$ & 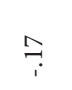 & $\stackrel{*}{\stackrel{*}{n}}$ & $\cong$ & $\stackrel{\vartheta}{\dddot{1}}$ & $\stackrel{\star}{\stackrel{\star}{*}}$ & ণ্ৰি & ô. & $\underset{i}{\sharp}$ & tr. & 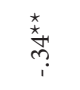 & $\stackrel{8}{i}$ & $\stackrel{2}{?}$ & 8 \\
\hline $\begin{array}{l}\text { Embedded } \\
\text { Fig. RT }\end{array}$ & $\stackrel{\substack{* \\
⿱ 亠 幺}}{i}$ & 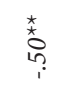 & 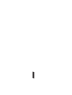 & $\stackrel{*}{\stackrel{*}{0}}$ & $\stackrel{\star \star H}{i}$ & 恚 & $\stackrel{\star}{\stackrel{*}{i}}$ & 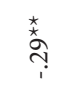 & $\underset{i}{0}$ & 8 & $\because$ & $\stackrel{\star *}{\stackrel{*}{*}}$ & $\stackrel{2}{\longrightarrow}$ & $\stackrel{20}{7}$ & o. & $\stackrel{7}{\because}$ & $\stackrel{?}{\because}$ & $\underset{i}{0}$ & $\because$ & రి. & $\stackrel{10}{\longrightarrow}$ & $\stackrel{n}{\sim}$ \\
\hline $\begin{array}{l}\text { Embedded } \\
\text { Fig.. acc. }\end{array}$ & 弆 & 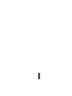 & 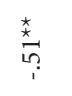 & 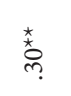 & 우 & $\stackrel{\star}{\stackrel{\star}{~}}$ & $\stackrel{n}{\longrightarrow}$ & 齐 & $\stackrel{9}{\hookrightarrow}$ & 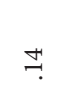 & $\hat{o}_{i}$ & 美 & $\dot{S}_{i}$ & $\stackrel{\star}{\text { స̦ }}$ & $\sigma_{i}$ & 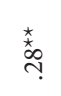 & o & $\stackrel{\infty}{\circ}$ & $\underset{i}{ت}$ & $\stackrel{n}{\stackrel{n}{!}}$ & $\stackrel{\overbrace{}}{i}$ & $\stackrel{\infty}{?}$ \\
\hline \multirow[t]{2}{*}{ Block Design } & , & $\begin{array}{l}\text { 希 } \\
\text { in }\end{array}$ & $\stackrel{*}{*}$ & 袁 & 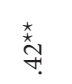 & $\stackrel{\sqrt[x]{\star}}{\stackrel{n}{n}}$ & 袁 & $\stackrel{\star \star ⿱}{\sharp}$ & $\stackrel{\substack{x \\
m}}{m}$ & $\stackrel{?}{\ddots}$ & $\exists$ & $\stackrel{\star \star ⿱ 亠 乂}{*}$ & $\stackrel{?}{i}$ & 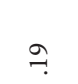 & $\stackrel{7}{\dddot{1}}$ & 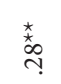 & $\dddot{7}$ & ঙ̣ & $\stackrel{\star x}{0}$ & ๕. & $\stackrel{\substack{* \\
\stackrel{m}{+}}}{i}$ & $\stackrel{\star}{*}$ \\
\hline & 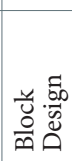 & 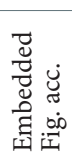 & 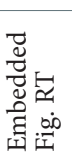 & 苞泀 & 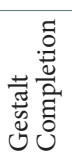 & 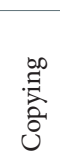 & 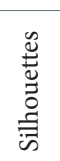 & 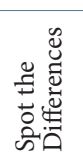 & 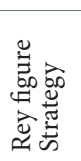 & 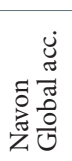 & 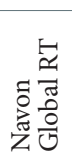 & 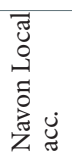 & 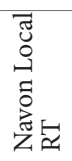 & 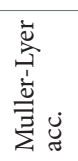 & 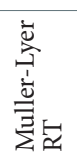 & 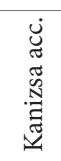 & 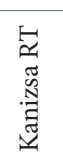 & 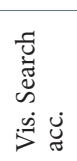 & $\begin{array}{l}\overrightarrow{\tilde{D}} \\
\overrightarrow{\tilde{J}} \\
\ddot{\omega} \\
\dot{\vec{s}} \vec{\sim}\end{array}$ & 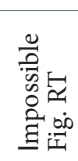 & 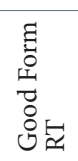 & 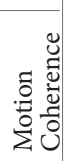 \\
\hline
\end{tabular}

Note. Zero-order correlations are below the diagonal $(d f=90)$. Partial correlations controlling for 2 -subtests WASI IQ and choice RT are above the diagonal in italics $(d f=86)$ ${ }^{*} p<.05$. two-tailed. ${ }^{* *} p<.01$, two-tailed. 
Preliminary analyses examined the suitability of the data for factor analysis which followed the recommendations of Field (2005). Bartlett's test of sphericity was highly significant $(\chi 2=514.4, d f=210$,

$p<.001)$, indicating some relationships existed between variables, which makes the correlation matrix suitable for factor analysis. Determinant of correlation matrix was .002 (well above the recommended minimum value of .00001) indicating that multicollinearity was not a problem. On the other hand the Kaiser-Meyer-Olkin measure of sampling adequacy was .653, which is above the minimum recommended value of .500 yet "mediocre" (Kaiser, 1974, as cited in Field, 2005). This indicates that the pattern of correlations was relatively diffuse, making it relatively hard to extract distinct and reliable factors. The analysis of anti-image correlation matrix diagonals, which indicate sampling adequacy of individual variables, brought unsatisfactory results $(<.50)$ for the Navon incompatible global RT. This variable was excluded from the analysis, which resulted in the improvement of sampling adequacy (Kaiser-Meyer-Olkin = .699).

Seven factors were extracted using Kaiser's criterion of eigenvalues greater than one. Together they explained $44.8 \%$ of total variance. Most communality values were lower than .50; that is the seven latent factors could typically account for less than half of the variance of individual variables. Only Block Design showed high communality values (above .80, see Table 5). The pattern matrix, representing coefficients of regression of variables on factors, is displayed in Table 6, while the structure matrix, representing factor loadings (coefficients of correlations between variables and factors), is displayed in Table 7 .

We interpreted the seven factors as follows:

Factor 1: Dis-embedding. This factor received six substantial (greater than .40) factor loadings, three of which (Block Design, Embedded Figures accuracy, and RT) were significant according to Stevens' (1992, p. 394) criteria for testing the statistical significance of factor loadings, which imply the critical value of .534 for $N=90$. Out of the six variables loading substantially on Factor 1, four (Embedded Figures accuracy and RT, Copying Test and Hidden Patterns Test) represent Carroll's (1993) Closure Flexibility factor, defined as "speed of detecting and dis-embedding a known stimulus array from a more complex array" (p. 341). The fifth variable, Spot the Differences, was not included in Carroll's analyses, but also appears to require dis-embedding. Only the sixth variable, Block Design (which was the highest loading Factor 1 variable), represents a different factor in Carroll's analysis, namely, Visualisation. Overall, we decided that the term disembedding offers the best description of the demands shared by the tasks loading on Factor 1, but we understand it as broadly equivalent to the concept of Closure Flexibility (Carroll, 1993), as well as weak central coherence (Frith, 1989), and field-independence (Witkin et al., 1962). Of the seven factors identified in our analysis, the Dis-embedding factor was the only one approaching Stevens' (1992, p. 395) criteria for a reliable factor (four or more loadings higher than .60). The remaining six factors are not considered reliable, thus their interpretation must remain tentative.

Factor 2: Global Bias. High scores on this factor represent primarily slow performance on the local level of the Navon Hierarchical Figures Test, and accurate performance on the global level of that test. This suggests the factor represents a general bias towards the global level of processing. This interpretation is supported by the fact that the factor is also weakly loaded with slow performance on

\section{TABLE 5}

Communalities in the First Factor Analysis

\begin{tabular}{lcc}
\hline Variables & Initial & Extraction \\
\hline Block Design & .701 & .830 \\
Group Embedded Figures Test accuracy & .408 & .474 \\
Group Embedded Figures Test RT & .534 & .543 \\
VOSP-Silhouettes & .228 & .176 \\
Gestalt Completion Test & .342 & .326 \\
Hidden Patterns Test & .330 & .381 \\
Copying Test & .341 & .359 \\
Spot the Differences Test & .398 & .460 \\
Rey figure: Copying strategy & .262 & .282 \\
Impossible Figures RT & .291 & .508 \\
Muller-Lyer illusory condition accuracy & .285 & .445 \\
Muller-Lyer illusory condition RT & .425 & .618 \\
Visual Search, target present within 25 distractors accuracy & .220 & .277 \\
Visual Search, target present within 25 distractors RT & .282 & .397 \\
Kanizsa illusory condition accuracy & .438 & .689 \\
Kanizsa illusory condition RT & .263 & .334 \\
Good Form experimental orthogonal RT & .445 & .559 \\
Navon Hierarchical Figures Test, incompatible, global acc & .336 & .378 \\
Navon Hierarchical Figures Test, incompatible, local acc & .290 \\
Navon Hierarchical Figures Test, incompatible, local RT & .374 & .312 \\
\hline
\end{tabular}




\section{TABLE 6.}

Pattern Matrix of the First Factor Analysis

\begin{tabular}{|c|c|c|c|c|c|c|c|}
\hline \multirow[t]{2}{*}{ Variables } & Factors & & & & & & \\
\hline & 1 & 2 & 3 & 4 & 5 & 6 & 7 \\
\hline Embedded Figures acc & .715 & & & & & & \\
\hline Embedded Figures RT & -.687 & & & & & & \\
\hline Block Design & .537 & & & & & .415 & \\
\hline Copying & .468 & & & & & & \\
\hline Navon local RT & & .771 & & & & & \\
\hline Navon global acc & & .501 & & & & & \\
\hline Muller-Lyer acc & & & .648 & & & & \\
\hline Kanizsa acc & & & .455 & -.597 & & & \\
\hline Kanizsa RT & & & & .504 & & & \\
\hline Spot the Differences & .370 & & & -.379 & & & \\
\hline Impossible Figures RT & & & & & .574 & & \\
\hline Visual Search acc & & & & & -.397 & & \\
\hline Gestalt Completion & & & & & & .485 & \\
\hline Rey figure strategy & & & & & & .480 & \\
\hline Good Form RT & & .313 & & .309 & & -.461 & \\
\hline Navon local acc & & & & & & .416 & \\
\hline VOSP-Silhouettes & & & & & & & \\
\hline Visual Search RT & & & & & & & -.603 \\
\hline Muller-Lyer RT & & & .465 & & & & -.508 \\
\hline Hidden Patterns & & & & & & & .402 \\
\hline
\end{tabular}

Note. Coefficients are sorted by size, those lower than .30 are not displayed.

\section{TABLE 7.}

Structure Matrix of the First Factor Analysis

\begin{tabular}{|c|c|c|c|c|c|c|c|}
\hline \multirow[t]{2}{*}{ Variables } & Factors & & & & & & \\
\hline & 1 & 2 & 3 & 4 & 5 & 6 & 7 \\
\hline Block Design & .779 & & & & -.334 & .689 & .351 \\
\hline Embedded Figures acc & .711 & & & & & & \\
\hline Embedded Figures RT & -.672 & & & & & & \\
\hline Copying & .514 & & & & -.359 & & \\
\hline Spot the Differences & .509 & & & -.495 & & .316 & \\
\hline Navon local RT & & .751 & & & & & \\
\hline Navon global acc & & .534 & & & & & \\
\hline Muller-Lyer acc & & & .624 & & & & \\
\hline Kanizsa acc & & & .549 & -.631 & & & \\
\hline Kanizsa RT & & & & .504 & & & \\
\hline Impossible Figures RT & & .379 & & & .561 & & \\
\hline Visual Search acc & & & & & -.404 & & \\
\hline Good Form RT & & .303 & & .370 & & -.537 & \\
\hline Navon local acc & .372 & & & & & .497 & \\
\hline Gestalt Completion & .302 & & & & & .489 & \\
\hline Rey figure strategy & & & & & & .487 & \\
\hline VOSP-Silhouettes & & & & & & .326 & \\
\hline Visual Search RT & & & & & & & -.602 \\
\hline Muller-Lyer RT & & .378 & .515 & & & & -.588 \\
\hline Hidden Patterns & .414 & & & & & & .497 \\
\hline
\end{tabular}

Note. Factor loadings are sorted by size, those lower than .30 are not displayed. Loadings that are statistically significant according to Stevens' (1992) interpretation are in bold. 
TABLE 8.

Factor Correlation Matrix of the Zero-Order Factor Analysis

\begin{tabular}{lcccccc}
\hline Factors & 1 & 2 & 3 & 4 & 5 & 6 \\
\hline 1 & - & & & & & \\
2 & .04 & - & & & & \\
3 & $.27^{* *}$ & .16 & - & & & \\
4 & $-.24^{*}$ & -.06 & -.08 & - & & \\
5 & -.15 & .03 & -.08 & -.01 & - & \\
6 & $.41^{* *}$ & .04 & .00 & -.20 & -.09 & - \\
7 & $.23^{*}$ & $-.25^{*}$ & -.04 & -.13 & -.09 & $.23^{*}$
\end{tabular}

Note. ${ }^{*} p<.05$, two-tailed. ${ }^{* *} p<.01$, two-tailed.

Muller-Lyer and Good Form tasks, where slowness would indicate global bias, that is, difficulty in dis-embedding. This interpretation is inconsistent however with a weak loading the factor receives from slow performance on the Impossible-Possible Figures Test, where slowness would indicate local bias(difficulty in integration of features).

Factor 3: This factor loads substantially with accuracy of performing Muller-Lyer and Kanizsa tasks. While high accuracy on the Muller-Lyer task indicates resistance to illusion, high accuracy on the Kanizsa task indicates sensitivity to illusory contours. This factor also received a substantial loading from Muller-Lyer RT, which may indicate a strategic choice for accuracy over speed (the Muller-Lyer task produced a trade-off between accuracy and speed: High accuracy is weakly $[r=.21, n s]$ correlated with slow performance). This factor is hard to interpret, as such we have not given it a specific label. However we tentatively suggest that it represents slow and careful task performance.

Factor 4: Kanizsa. Since high scores on this factor represent primarily low accuracy and slow speed of performing the Kanizsa task, it may be interpreted as representing task-specific competence (or, more precisely, lack of competence) on the Kanizsa task. High scores on this factor also represent low accuracy on the Spot the Differences Test and slow performance of the Good Form Task.

Factor 5: Perceptual Integration. This factor received substantial loading from Impossible Figures RT and Visual Search accuracy, and moderate loadings from the Copying and Block Design tasks. High scores on this factor represent poor, inaccurate, and slow performance on these tasks. Since all of these tasks appear to share the demand for the efficient integration of visual features, the factor may represent (poor) integration ability.

Factor 6: Cognitive Flexibility. This factor received substantial loadings from Block Design, Good Form RT, Navon local accuracy, Gestalt Completion Test, Rey figure strategy, as well as moderate loadings from the VOSP-Silhouettes and Spot the Differences Test. While these variables are heterogeneous, most seem to share the demand for dis-embedding similar to that tapped by Factor 1. Indeed, some variables load on both factors (especially Block Design), and both factors are moderately correlated (see below). Alternatively, Factor 6 could represent more general cognitive flexibility namely the ability to flexibly allocate attentional resources to optimise task performance (Booth \& Happé, personal communication, February 2007).

Factor 7: Perceptual Speed/Local Bias. This factor receives substantial loadings from Visual Search and Muller-Lyer RTs as well as the Hidden Patterns Test. Carroll (1993) identified tasks that require speed in searching for and finding or correctly comparing stimuli which can be arranged by pairs, columns, rows, or at random, as representing the factor of Perceptual Speed. This description seems to apply to our Visual Search task (where the target stimulus must be found quickly amongst the array of distractors), and Muller-Lyer task (where the rapid comparison of the length of two lines is required). Although the Hidden Patterns Test has been identified by Carroll, and in our own analysis, as representing Closure Flexibility (Dis-embedding), it also requires speeded search and comparison of stimuli, which may explain why it also loads equally strongly on Factor 7 . All three variables mentioned above also appear to favour a local processing style.

Analysis of correlations between factors (see Table 8) indicates that they are largely orthogonal. The only moderate $(r=.41)$ correlation occurred between Factors 1 (Dis-embedding) and 6 (Cognitive Flexibility). Factor 1 is also weakly positively associated with Factors 3 (unnamed), 7 (Perceptual Speed / Local Bias), and 4 (Kanizsa). While the last correlation is negative it represents a positive relationship: Good ability to dis-embed (Factor 1) scores are associated with good (accurate and/or fast) performance on the variables that load onto Factor 4 (primarily Kanizsa and Spot the Differences). Additionally, Factor 7 (Perceptual Speed / Local Bias) is weakly correlated with Factors 2 (Global Bias) and 6 (Cognitive Flexibility).

\section{TABLE 9.}

Factor Correlation Between Factor Scores and Background Variables

\begin{tabular}{|c|c|c|c|c|c|c|c|}
\hline \multirow[b]{2}{*}{ Variables } & \multicolumn{7}{|c|}{ Factor } \\
\hline & 1 & 2 & 3 & 4 & 5 & 6 & 7 \\
\hline Motion Coherence & $-.26^{*}$ & -.12 & -.11 & .01 & $.28^{* *}$ & -.16 & -.06 \\
\hline Form Coherence & $-.21^{*}$ & -.14 & -.11 & $.24^{*}$ & -.02 & $-.29 * *$ & -.17 \\
\hline Choice RT & -.01 & $.31^{* *}$ & -.02 & $.30^{* *}$ & .02 & -.11 & -.08 \\
\hline WASI IQ & $.22^{*}$ & .05 & $.27^{* *}$ & -.09 & -.08 & .10 & .12 \\
\hline
\end{tabular}

Note. Factor scores were estimated using regression method.

${ }^{*} \mathrm{p}<.05$, two-tailed. ${ }^{* *} \mathrm{p}<.01$, two-tailed. 
The first of these two correlations is negative, that is, higher perceptual speed/local bias is associated with reduced global bias.

Correlations between factor scores and the baseline/psychophysical variables (form and motion coherence thresholds, IQ, and choice RT) were generally weak (see Table 9). The only moderate (.30 or above) correlations were observed between choice RT and Factors 2 (Global Bias) and 4 (Kanizsa); high scores on those factors are associated with slower choice reaction times. IQ correlated weakly with Factors 1 (Dis-embedding) and 3 (unnamed). The Motion and Form Coherence tests were threshold tests, therefore a high score represents poor performance and a low score represents good performance. The negative correlations between Factor 1 (Dis-embedding) and these tests indicate that the individuals who are good at dis-embedding tend to be good at detecting both the coherent motion and coherent form signals. The positive correlation between Factor 4 (Kanizsa) and form coherence thresholds indicates that good performance on the tasks that load onto this factor is related to good sensitivity to coherent form. The positive correlation between motion coherence thresholds and Factor 5 (Integration) indicates that good integration is related to good sensitivity to coherent motion. Finally, the negative correlation between Factor 6 (Cognitive Flexibility) and Form Coherence indicates that high cognitive flexibility is related to high sensitivity to detect coherent form. Overall, however, there is no evidence that any of the seven factors identified in our analysis reflect primarily the low level efficacy of visual perception, speed of choice reaction, or general intelligence.

The preceding analyses suggested that the extracted factors represent mainly specific dimensions of visual perception, and are only weakly loaded with more general aspects of cognition (namely general intelligence or general speed of processing). However, in order to obtain the factorial structure of visual cognition that is independent from any influence of those general factors, another factor analysis was run to control for individual differences in IQ and choice RT. The second analysis was based on the matrix of standardised residuals, remaining after the scores of visual perception tests were regressed on general intelligence (WASI IQ based on two subtests) and general speed of processing (Choice RT) scores. The results were not substantially different to the factor analysis reported above and are presented in Appendix C.

Following the suggestion of one of the reviewers, we also analysed the data using the confirmatory factor analysis (CFA). Two models were tested against the data: (a) a single factor model, testing the prediction that all variables represent a single continuum of global-local perceptual bias; (b) a two factor model, testing the prediction of distinct "global" and "local" dimensions of visual perception. Individual variables were allocated to either "global" or "local" factors, depending on our analysis of the task demands. We classified the following variables as measuring global perceptual style: Gestalt Completion, VOSP silhouettes, Rey Figure strategy, Impossible Figures RT, Navon (incompatible) Global accuracy and RT, and Kanizsa accuracy and RT. The remaining variables (Block Design, Embedded Figures Task accuracy and RT, Copying, Spot the Difference, Navon [incompatible] Local accuracy and RT, Muller-Lyer accuracy and RT, Visual Search accuracy and RT, and Good Form RT) were classified as measuring local perceptual styles. The "global" and "local" factors were assumed to be correlated. The analyses were carried out using AMOS software.

For the first, single factor analysis, the CFA algorithm failed to converge at all; no solution was obtained. The second, two factor model provided a poor fit to the data (according to Blunch's, 2008, and Byrne's, 2001, interpretation): The parameter estimates were not statistically significant, and the fit indices were unsatisfying, $\chi^{2}(169)=$ $317.1, p<.001$; CFI $=.561$; RMSEA $=.099$ ). Thus, it can be concluded that the model is considerably different from the data. While both models could be modified to improve their fit to the data (by removing certain variables from the analysis, and adding or deleting parameters), the basic fact remains: Neither a single factor nor a two factor model represent the data well - a conclusion consistent with the results of our exploratory factor analysis.

\section{DISCUSSION}

The aim of this study was to investigate the relationships within a set of tasks that are commonly described in the literature as measuring (weak) central coherence/field-(in)dependence (Frith, 1989, 2003; Witkin et al., 1962) as well as related, but typically poorly defined, constructs of global and local perception. Many studies have investigated these constructs, primarily in the context of autism (e.g., see Happé \& Frith, 2006), but also in dyslexia (e.g., Brosnan et al., 2002; von Karolyi et al., 2003) and typical adult cognition (see Carroll, 1993). However, there have been very few attempts to clarify the relationship between these constructs, or to validate the tasks purported to operationalise them. We investigated this issue by surveying the literature on (weak) central coherence/field-(in)dependence, global and local perception; identifying a set of visual only tasks that are used to measure these constructs, and, finally, measuring the strength and direction of the relationship between them in a group of typically functioning adults.

Our search for the relevant tasks was made harder by the conceptual and terminological inconsistencies apparent in the literature. We identified the following predominant (if sometimes implicit) assumptions. The terms (weak) central coherence and field-(in)dependence are synonymous and represent the tendency to dis-embed elements from the surrounding context, and to segment local details from the global configuration. Broadly speaking, individuals who show weak central coherence/field-independence could be considered as having a locally biased perceptual style. This is in contrast to those with a more globally biased perceptual style, that is people who are strongly influenced by the surrounding context and would be described as having strong central coherence/being field-dependent.

Despite the implicit assumption within the literature that weak central coherence/field-independence is equivalent to a locally biased perceptual style and strong central coherence/field-dependence is equivalent to a globally biased perceptual style, the direct relationship between these constructs has not been examined systematically. We hypothesised that three potential outcomes were possible from our exploratory factor analyses: 
1. All tasks would load on a single factor, representing a continuum of weak to strong central coherence (field-independent to field-dependent; local to global perceptual style). This factor would receive positive loading from tasks that are easier to complete for those who have a locally biased perceptual style, and negatively loaded with tasks that are easier to complete for those who have a globally biased perceptual style.

2. Local (field-independent) and global (field-dependent) tasks would load onto two separate and uncorrelated factors, indicating that local or global bias do not occur on a continuum but in fact represent independent dimensions of visual cognition.

3. The tasks would share little variance. Several different factors would emerge; they would represent some very narrow aspects of visual cognition, or be merely task-specific.

The first hypothesis is consistent with the assumptions we identified in the literature. However the outcome of our analyses was largely consistent with the third hypothesis. It revealed that the tasks share relatively little variance - contrary to what would be expected if they measured a single construct. The factor analyses identified as many as seven factors, only one of which could be considered reliable (Stevens, 1992). This reliable first factor, which we labelled "Dis-embedding", received substantial loading from the Block Design and Group Embedded Figures Tests. It corresponded closely to the concepts of field-independence/weak central coherence as defined by Witkin et al. (1962) and Frith (1989) which they operationalized with the Embedded Figures and Block Design tests. However, this factor captured only a relatively small proportion of overall variance, and some of the tasks that can be construed as representing weak central coherence or field-independence by virtue of a priori task analysis, and/or previous definition in the research literature (e.g., Visual Search and Muller-Lyer), did not load onto this factor.

Factor 1 (Dis-embedding) also broadly replicated the Closure Flexibility factor identified in Carroll's survey, defined as "speed of detecting and dis-embedding a known stimulus array from a more complex array" (Carroll, 1993, p. 341). Carroll identified Embedded Figures, Copying and Hidden Patterns among tests of closure flexibility, all of which loaded substantially on our Factor 1. Our results differed from Carroll's in just one aspect: Whereas in our analysis the Block Design task was the highest-loading task on Factor 1, in Carroll's analysis it belonged to a separate factor of Visualisation, defined as "the ability to comprehend imaginary movements in a 3D space, or the ability to manipulate objects in imagination" (Carroll, 1993, pp. 315-316). However, since our battery included no other tasks, apart from Block Design, that met the definition of visualisation, and since the Visualisation and Closure Flexibility factors are hard to distinguish empirically (Carroll, 1993, pp. 338-339) our outcome is not necessarily at odds with Carroll's. Furthermore, the Block Design task, which was described very well by our seven factors (communality of over $80 \%$ ), appears to have a multifactorial structure, as it loaded substantially and significantly onto two factors, and moderately on a further two.

While local perception is reasonably well represented by the tasks that load on Factor 1 (Dis-embedding) and to some degree Factor 7
(Local Bias/Perceptual Speed), the tasks that we initially identified as representing global perception do not show a clear pattern of factor loadings. Only some of these tasks were represented by our factors, and these factors (Factor 2: Global Bias and Factor 5: Integration) appear to represent different constructs. Their interpretation is far from straightforward. We interpreted Factor 2 as representing global perception, since it received loadings from variables that represented global advantage and global interference in the Navon Hierarchical Figures Test, and increased reaction time to judge line length in the Muller-Lyer illusion. In the first factor analysis, the Gestalt Completion Test also loaded weakly onto this factor, but in the second analysis this dropped out and was replaced by a globally biased Rey figure copying style. Note, however, that the positive loading of Impossible Figures $\mathrm{RT}$ is inconsistent with the interpretation of Factor 2 as representing global perception as high RT on this task represents reduced integrative ability. The tasks that loaded onto Factor 5 (Impossible Figures, Visual Search, Copying, Block Design) appear to require efficient integration; either of contiguous line elements (Impossible Figures), or of within-element features, for example shape and colour, as in the Visual Search Task. The interpretation of Factor 5 as representing integration, draws on previous literature (e.g., Duncan, 1995) which suggests that Visual Search requires efficient integration of features. However, this is integration in a broader sense than outlined in the introduction. Tasks that we initially identified as requiring the integration or grouping of discrete elements (e.g., Good Form Task, Gestalt Completion Test, and Kanizsa task) did not load onto Factor 5, nor onto any discrete factor which could represent global grouping or Gestalt perception.

It is important to note that the pattern of factor loadings reported here is unlikely to reflect individual differences in either IQ or general speed of making choice reactions. These two variables showed generally weak correlations with performance individual perceptual style tasks (see Table 4) and the extracted factors (see Table 9). Moreover, the second factor analysis which specifically controlled for the effects of IQ and choice RT produced results very similar to the first. Whilst we cannot be sure we eliminated Spearman's $g$ factor completely from our analysis, since only two tasks, Matrix Reasoning and Vocabulary, were used to measure it, we can be certain that this was not the main source of variance that was captured. What we captured was much more specific to visual perception.

The pattern of correlations and factor loadings obtained in our analyses speaks against the idea of a single continuum from global to local bias, synonymous with the continuum of central coherence or that of field dependence-independence. Our data suggest that, instead, central coherence and field dependence-independence should be understood more narrowly, as the capacity for dis-embedding only, which is not related to capacity for integration, gestalt grouping, or global perception. This outcome is consistent with some autism studies, which also demonstrate that in autism, one's ability to dis-embed has relatively little bearing on performance on tasks that measure global perception (see Mottron, Dawson, Souliéres, Hubert, \& Burack, 2006, who raise the point that enhanced local perception in autism does not necessarily imply reduced global perception in autism). 
While individual differences in dis-embedding ability appear to have little in common with one's tendency towards global perception, they may be related to other factors, namely slow and careful task performance, represented on Factor 3, and cognitive flexibility, represented on Factor 6.

Given that we find support for a narrowly defined construct of weak central coherence/field-independence the question as to what underpins this construct on the psychophysiological level must be considered. In an attempt to uncover the origin of weak central coherence in autism, a range of theoretical positions have been advanced. For example, based on evidence of superior visual search for a conjunctive target in autism, it has been suggested that weak central coherence may develop from enhanced perceptual discrimination (O'Riordan \& Plaisted, 2001), or enhanced perceptual functioning underpinned by over-activity in area V1 (Mottron et al., 2006). However, the implication that weak central coherence/field-independence in the typical population emerges from enhanced discrimination is not supported by the data from neuro-typical adults presented here, as performance on the Visual Search and Embedded Figures tasks were not significantly related (see Table 4; although see Jarrold et al., 2005, who have reported such a relationship in children). It has also been suggested that weak central coherence in autism emerges from reduced global grouping, specifically in the dorsal stream. This claim is based on evidence that in children with autism, performance on the Embedded Figures Test is related to ability to detect global motion (Pellicano, Gibson, et al., 2005); that is, children who are better at identifying embedded figures are less sensitive to global motion (reduced sensitivity to global motion is interpreted to reflect abnormality within the dorsal stream). However, this model is not supported by the data presented here as we found an opposite relationship: The correlation between Factor 1, representing good performance on the Group Embedded Figures Test (weak central coherence), and Motion and Form Coherence Thresholds was negative (see Table 9). The correlations between Motion or Form Coherence Thresholds and Group Embedded Figures Test accuracy were also negative (see Table 4). That is, the more field-independent the individual, the more able they were to integrate the target elements of either the motion or form signal.

In conclusion, the results of our exploratory factor analysis indicate that the 14 tasks we selected based on their use in the literature for measuring (weak) central coherence/field-(in)dependence or global/ local perceptual style do not measure a unitary construct. However, we did find evidence in favour of the existence of a relatively narrow factor that represents individual differences in the ability to dis-embed relevant visual stimuli - the construct that largely corresponds to the notion of weak central coherence/field-independence, and partly also to the concept of Closure Flexibility (Carroll, 1993). In contrast, global grouping as defined by the ability to pull detached elements into a coherent whole was not represented by a single factor. Indeed, both task analysis and the outcome of the factor analysis suggests that multiple processes are involved in perceptual integration. Given that there was no significant relationship between Factor 1 and Factors 2 and 5, our results suggest that dis-embedding (or weak central coherence or field-independence) does not predict reduced global perception.

While the conclusions reached here apply directly to the adult neuro-typical population only, they may have implications for the studies of cognitive development and developmental disorders, especially autism. This is definitely so if we assume that central coherence/field dependence is a general characteristic of human cognition, and that individuals with autism represent the tail end of the normal distribution of that characteristic; that is they are different from neuro-typical individuals in degree rather than kind. If this is the case, then studies of the autism population would be expected to reveal a similar pattern of correlations to the one observed here. An alternative possibility is that all individuals with autism (or a subgroup of individuals) are qualitatively different in their cognitive skills either because of some specific deficit, or enhancement (e.g., Caron et al. 2006). If the latter is the case, then the data from our neuro-typical population may not be extrapolated easily to the autism population and much stronger associations between the tasks may, or may not, be apparent within individuals with autism. The current study cannot speak to this directly. However, it definitely makes the case for methodological caution: It is unsafe to operationalise the concepts of global and local perceptual styles purely on the basis of a priori task analysis, without empirical validation. Indeed, even defining these concepts precisely requires such validation.

\section{FOOTNOTES}

${ }^{1}$ The Visual Search Task was an exception as the stimuli were either red or green. In this case the task was not completed by the colour blind participant.

\section{AUTHOR NOTE}

Elizabeth Milne, Department of Psychology, The University of Sheffield. Marcin Szczerbinski, Department of Human Communication Sciences, The University of Sheffield.

This work was financially supported by the faculty of Social Science at The University of Sheffield. We gratefully acknowledge the assistance of Jana Dankovicova, Laura Earle, Vicki Hayman, Hwan-Cui Koh, Alison Scope, Hayley Smith, and Meghana Wadnerkar, who collected the data presented here, and Laura Earle and Ania Czyż for assisting in data entry and double scoring. Mike Coleman at the department of Human Communication Science, University College London programmed the visual basic tasks and Peter Hansen at the Laboratory of Physiology, University of Oxford, provided the motion and form coherence tasks. Catya von Karolyi, at the Department of Psychology, University of Wisconsin,Eau Claire provided the stimuli for the Impossible-Possible figures task, and Izabela Pietras at the Department of Psychology, Marie-Curie University in Lublin, Poland, provided the materials for the Spot-the-Difference task. Silke Fricke from the Department of Human Communication Sciences, University of Sheffield assisted us with the confirmatory factor analysis. We thank Rhonda Booth and Francesca Happé for a useful discussion of the data presented here, and Simon Hamilton for proof reading the manuscript. 


\section{REFERENCES}

Booth, R. (2006). Local-global processing and cognitive style in autism spectrum disorder and typical development. Unpublished $\mathrm{PhD}$ thesis, King's College London.

Booth, R., Charlton, R., Hughes, C., \& Happé, F. (2003). Disentangling weak coherence and executive dysfunction: Planning drawing in autism and attention-deficit/hyperactivity disorder. Philosophical Transactions of the Royal Society of London Series B - Biological Sciences, 358, 387- 392. WwW

Blunch, N. J. (2008). Introduction to structural equation modelling using SPSS and AMOS. London: Sage Ltd.

Brosnan, M., Demetre, J., Hamill, S., Robson, K., Shepherd, H., \& Cody, G. (2002). Executive functioning in adults and children with developmental dyslexia. Neuropsychologia, 40, 2144$2155 . \underline{W W}$

Brosnan, M., Scott, F. J., Fox, S., \& Pye, J. (2004). Gestalt processing in autism: Failure to process perceptual relationship and the implications for contextual understanding. Journal of Child Psychology and Psychiatry, 45, 459-469. Www

Burnette, C. P., Mundy, P. C., Meyer, J. A., Sutton, S. K., Vaughan, A. E., \& Charak, D. (2005). Weak central coherence and its relations to theory of mind and anxiety in autism. Journal of Autism and Developmental Disorders, 35, 63-73.

Byrne, B. M. (2001). Structural equation modelling with AMOS: Basic concepts, applications and programming. Mahwah, NJ: Lawrence Erlbaum Associates Inc.

Carroll, J. B. (1993). Human cognitive abilities: A survey of factoranalytic studies. Cambridge: Cambridge University Press.

Caron, M. J., Mottron, L., Berthiaume, C., \& Dawson, M. (2006). Cognitive mechanisms, specificity and neural underpinnings of visuospatial peaks in autism. Brain, 129, 1789-1802. WwW

Chapman, D. M., \& Calhoun, J. G. (2006). Validation of learning style measures: Implications for medical education practice. Medical Education, 40, 576-583. Www

Duncan, J. (1995). Target and nontarget grouping in visual search. Perception and Psychophysics, 57, 117-120. WwW

Edgin, J., \& Pennington, B. (2005). Spatial cognition in autism spectrum disorders: Superior, impaired, or just intact? Journal of Autism and Developmental Disorders, 35, 729-745. WWw

Ekstrom, R., French, J. W., Harman, H. H., \& Derman, D. (1976). Kit of factor-referenced cognitive tests. Princeton, New Jersey: Educational Testing Service.

Fabrigar, L. R., Maccallum, R. C., Wegener, D. T., \& Strahan, E. J. (1999). Evaluating the use of exploratory factor analysis in psychological research. Psychological Methods, 4, 272-299.

Field, A. (2005). Discovering statistics using SPSS (2nd ed.). London: Sage Publications.

Frith, U. (1989). Autism: Explaining the enigma. Oxford: Blackwell Scientific Publications.

Frith, U. (2003). Autism: Explaining the enigma (2nd ed.). Oxford: Blackwell Scientific Publications.

Hansen, P. C., Stein, J. F., Orde, S. R., Winter, J. L., \& Talcott, J. B.
(2001). Are dyslexics' visual deficits limited to measures of dorsal stream function? Neuroreport, 12, 1527-1530. Www

Happé, F. (1996). Studying weak central coherence at low levels: Children with autism do not succumb to visual illusions. A research note. Journal of Child Psychology and Psychiatry, 37, 873-877. $\overline{\text { WWW }}$

Happé, F., \& Frith, U. (2006). The weak coherence account: Detailfocused cognitive style in autism spectrum disorders. Journal of Autism and Developmental Disorders, 36, 5-25. WWW

Jarrold, C., Gilchrist, I., \& Bender, A. (2005). Embedded figures detection in autism and typical development: Preliminary evidence of a double dissociation in relationships with visual search. Developmental Science, 8, 344-351. [Ww

Kaernbach, C. (1991). Simple adaptive testing with the weighted up-down method. Perceptual Psychophysics, 49, 227-229.|www

Kanizsa, G. (1974). Contours with gradients or cognitive contours? Italian Journal of Psychology, 1, 93-112.

Lezak, M. D., Howieson, D. B., Loring, D. W., Hannay, H. J., \& Fischer, J. S. (2004). Neuropsychological assessment (4th ed.). Oxford: Oxford University Press.

Milne, E., \& Scope, A. (2008). Are children with autistic spectrum disorders susceptible to contour illusions? British Journal of Developmental Psychology, 26, 91-102.

Mooney, C. M. (1957). Age in the development of closure ability in children. Canadian Journal of Psychology, 11, 219-226.

Mottron, L., Belleville, S., \& Menard, E. (1999). Local bias in autistic subjects as evidenced by graphic tasks: Perceptual hierarchization or working memory deficit? Journal of Child Psychology and Psychiatry, 40, 743-755.

Mottron, L., Dawson, M., Souliéres, I., Hubert, B., \& Burack, J. A. (2006). Enhanced perceptual functioning in autism: An update and eight principles of autistic perception. Journal of Autism and Developmental Disorders, 36, 27-43.

Navon, D. (1977). Forest before trees: The precedence of global features in visual perception. Cognitive Psychology, 9, 353383.

Nisbett, R. E., \& Miyamoto, Y. (2005). The influence of culture: Holistic versus analytic perception. Trends in Cognitive Sciences, 9, 467-473.

O'Riordan, M., \& Plaisted, K. (2001). Enhanced discrimination in autism. The Quarterly Journal of Experimental Psychology A, 54, 961 - $979 . \widehat{\text { Www }}$

Osterrieth, P. A. (1944). Le test de copie d'une figure complexe [The complex figure copy test]. Archives de Psychologie, 30, 206-356.

Pellicano, E., Gibson, L., Maybery, M., Durkin, K., \& Badcock, D. R. (2005). Abnormal global processing along the dorsal visual pathway in autism: A possible mechanism for weak central coherence? Neuropsychologia, 43, 1044-1053. Www

Pellicano, E., Maybery, M., \& Durkin, K. (2005). Central coherence in typically developing preschoolers: Does it cohere and does it relate to mindreading and executive control? Journal of Child 
Psychology and Psychiatry, 46, 533 - 547.

Pellicano, E., Maybery, M., Durkin, K., \& Maley, A. (2006). Multiple cognitive capabilities/deficits in children with an autism spectrum disorder: 'Weak' central coherence and its relationship to theory of mind and executive control. Development and Psychopathology, 18, 77-98. $\overline{\text { WWW }}$

Plaisted, K., O'Riordan, M., \& Baron-Cohen, S. (1998). Enhanced visual search for a conjunctive target in autism: A research note. Journal of Child Psychology and Psychiatry and Allied Disciplines, 39, 777-783.

Ringach, D. L., \& Shapley, R. (1996). Spatial and temporal properties of illusory contours and amodal boundary completion. Vision Research, 36, 3037-3050.

Ropar, D., \& Mitchell, P. (1999). Are individuals with autism and Asperger's syndrome susceptible to visual illusions. Journal of Child Psychology and Psychiatry, 40, 1283-1293.

Ropar, D., \& Mitchell, P. (2001). Susceptibility to illusions and performance on visuospatial tasks in individuals with autism. Journal of Child Psychology and Psychiatry, 42, 539-549. WWw

Schacter, D. L., Cooper, L. A., \& Delany, A. (1990). Implicit memory for unfamiliar objects depends on access to structural descriptions. Journal of Experimental Psychology: General, 119, 3-19. WWW

Shah, A., \& Frith, U. (1983). An islet of ability in autistic children: A research note. Journal of Child Psychology and Psychiatry and Allied Disciplines, 24, 613-620.

Shah, A., \& Frith, U. (1993). Why do autistic individuals show superior performance on the block design task? Journal of Child Psychology and Psychiatry, 34, 1351-1364. [. $\overline{\mathrm{wW}}$

Shorr, J. S., Delis, D. C., \& Massman, P. J. (1992). Memory for the Rey-Osterrieth figure: Perceptual clustering, encoding, and storage. Neuropsychology, 6, 43-50.

Stevens, J. P. (1992). Applied multivariate statistics for social sciences (2nd ed.). Hillsdae, NJ: Erlbaum.

Street, R. F. (1931). A gestalt completion test. New York: Teachers College, Columbia University.

Strupczewska, B. (1990). Test figury złożonej Reya-Osterreitha.
Podręcznik [Rey-Osterreigth complex figure. Test manual]. Warszawa: Centralny Ośrodek Metodyczny Poradnictwa Wychowawczo-Zawodowego MEN.

Tabachnick, B. G., \& Fidell, L. S. (2001). Using multivariate statistics (4th ed.). Boston: Allyn and Bacon.

Teunisse, J. P., Cools, A., van Spaendonck, K., Aerts, F., \& Berger, H. (2001). Cognitive styles in high-functioning adolescents with autistic disorder. Journal of Autism and Developmental Disorders, 31, 55-66.

Thurstone, L. L. (1944). A factorial study of perception. Chicago: University of Chicago Press.

von Karolyi, C., Winner, E., Gray, W., \& Sherman, G. F. (2003). Dyslexia linked to talent: Global visual spatial ability. Brain and Language, 85, 427-431.

Warrington, E. K., \& James, M. (1991). Visual object and space perception battery. Bury St. Edmunds, UK: Thames Valley.

Wasserstein, J., Barr, W. B., Zappulla, R., \& Rock, D. (2004). Facial closure: Interrelationship with facial discrimination, other closure tests, and subjective contour illusions. Neuropsychologia, 42, 158-163.

Wechsler, D. (1999). Wechsler abbreviated scale of intelligence. The Psychological Corporation.

Williams, M. C., \& Bologna, N. B. (1985). Perceptual grouping in good and poor readers. Perception and Psychophysics, 38, 367374. $\underline{\text { WW }}$

Witkin, H. A., \& Asch, S. E. (1948). Studies in space orientation: I. Further experiments on perception of the upright with displaced fields. Journal of Experimental Psychology, 38, 762-782. WWW

Witkin, H. A., Dyk, R. B., Faterson, H. F., Goodenough, D. R., \& Karp, S. (1962). Psychological differentiation: Studies of development. New York: John Wiley \& Sons, Inc.

Witkin, H. A., Oltman, P. K., Raskin, E., \& Karp, S. (1971). A manual for the embedded figures test. California: Consulting Psychologists Press.

RECEIVED 20.12.2008 | ACCEPTED 06.02.2009 


\section{APPENDIX A. DESCRIPTIVE STATISTICS}

\begin{tabular}{|c|c|c|c|c|c|}
\hline Measure & M & $M d n$ & $S D$ & Min-Max & $N$ \\
\hline Embedded Figures - accuracy & 15.14 & 16.5 & 3.65 & $3-18$ & 88 \\
\hline Embedded Figures - time (seconds) & 462.17 & 465.5 & 98.83 & 207-600 & 88 \\
\hline Hidden Patterns - accuracy & 82.25 & 83 & 18.5 & $43-131$ & 89 \\
\hline Gestalt Completion - accuracy & 14.21 & 15 & 2.67 & $4-19$ & 89 \\
\hline Copying - accuracy & 20.06 & 19 & 7.17 & $5-42$ & 89 \\
\hline Silhouettes - accuracy & 21.58 & 21 & 3.28 & $12-28$ & 89 \\
\hline Spot the Differences - accuracy & 15.51 & 16 & 4.93 & $2-28$ & 88 \\
\hline Rey figure - copying strategy & 13.69 & 14 & 4.11 & $5-19$ & 75 \\
\hline (Navon) HFT global incompatible acc. & 21.26 & 22 & 2.31 & $13-24$ & 88 \\
\hline (Navon) HFT global incompatible RT (ms) & 588.62 & 560 & 161.75 & $383-1683$ & 88 \\
\hline (Navon) HFT local incompatible acc. & 16.18 & 17 & 4.73 & $5-24$ & 88 \\
\hline (Navon) HFT local incompatible RT (ms) & 726.14 & 694.5 & 144.55 & $442.5-1185$ & 88 \\
\hline Muller-Lyer illusory condition - accuracy & 13.10 & 13 & 4.29 & $3-23$ & 86 \\
\hline Muller-Lyer illusory condition RT (ms) & 1546.63 & 1476.5 & 550.32 & $704-3138$ & 86 \\
\hline Kanizsa illusion - accuracy & 49.92 & 51 & 4.43 & $25-54$ & 86 \\
\hline Kanizsa illusion - RT (ms) & 698.33 & 677.3 & 135.57 & $415-1271$ & 86 \\
\hline Visual Search (25 distractors) - accuracy & 8.68 & 9 & 1.27 & $4-10$ & 81 \\
\hline Visual Search (25 distractors) - RT (ms) & 1056.22 & 1036 & 249.84 & $551-1694$ & 81 \\
\hline Impossible Figures - RT & 1955.40 & 1551 & 1354.48 & 646-7094.5 & 88 \\
\hline Good Form (orthogonal experimental - RT (ms) & 591.95 & 561.25 & 134.19 & $424.5-1139$ & 86 \\
\hline Choice RT (ms) & 372.92 & 373 & 46.56 & $261-545.6$ & 87 \\
\hline Motion Coherence (\% threshold) & 7.82 & 7.25 & 3.05 & $3.27-21.63$ & 88 \\
\hline Form Coherence (\% threshold) & 20.74 & 20.72 & 4.11 & $12.87-31.5$ & 88 \\
\hline \multicolumn{6}{|l|}{ Wechsler Abbreviated Scale of Intelligence } \\
\hline Vocabulary - raw score & 66.40 & 68 & 7.53 & $41-79$ & 88 \\
\hline Vocabulary - T-score & 63.43 & 66 & 8.50 & $33-76$ & 88 \\
\hline Block Design - raw score & 60.44 & 62.5 & 8.32 & $38-71$ & 88 \\
\hline Block Design - T-score & 61.08 & 62 & 5.70 & $47-69$ & 88 \\
\hline Similarities - raw score & 40.26 & 41 & 3.77 & $30-48$ & 88 \\
\hline Similarities - T-score & 59.05 & 60 & 6.61 & $41-72$ & 88 \\
\hline Matrix Reasoning - raw score & 29.85 & 30 & 2.82 & $20-35$ & 88 \\
\hline Matrix Reasoning - T-score & 58.18 & 59 & 5.67 & $40-69$ & 88 \\
\hline Verbal IQ & 119.18 & 121 & 11.87 & $86-140$ & 88 \\
\hline Performance IQ & 116.39 & 118 & 9.24 & $93-136$ & 88 \\
\hline General IQ based of 4 subtests & 119.84 & 120 & 9.30 & $100-137$ & 88 \\
\hline General IQ based of 2 subtests & 119.28 & 118 & 9.73 & $90-136$ & 88 \\
\hline
\end{tabular}




\section{APPENDIX B. PRELIMINARY TASK ANALYSIS}

\begin{tabular}{|c|c|c|}
\hline Task and effects & Statistical analyses and their results & \\
\hline Navon Hierarchical Figures Task & $\begin{array}{l}2 \times 3 \text { repeated measures ANOVA: Hierarchical Level (local or global) } \\
\times \text { Stimulus Type (compatible, neutral, or incompatible) }\end{array}$ & \\
\hline \multicolumn{3}{|l|}{ Accuracy } \\
\hline Main effect of hierarchical level & Higher when the target appeared at the global level & $F(1,87)=89.9, p<.01$ \\
\hline Main effect of stimulus type & Compatible $>$ Neutral $>$ Incompatible & $F(2,174)=187.7, p<.01$ \\
\hline Interaction & $\begin{array}{l}\text { The relative disadvantage caused by incompatible stimuli was greater } \\
\text { when the target appeared at the local level }\end{array}$ & $F(2,174)=51.7, p<.01$ \\
\hline \multicolumn{3}{|l|}{ Response time } \\
\hline Main effect of hierarchical level & Quicker when the target appeared at the global level & $F(1,87)=132.7, p<.01$ \\
\hline Main effect of stimulus type & Compatible $<$ Neutral $<$ Incompatible & $F(2,174)=153.6, p<.01$ \\
\hline Interaction & $\begin{array}{l}\text { The relative disadvantage caused by incompatible stimuli was greater } \\
\text { when the target appeared at the local level }\end{array}$ & $F(2,174)=14.9, p<.01$ \\
\hline Muller-Lyer Illusion Task & $\begin{array}{l}\text { Paired sample } t \text {-test comparing the illusory and non-illusory } \\
\text { conditions }\end{array}$ & \\
\hline Accuracy & Higher in the non-illusory condition & $t(85)=10.2, p<.05$ \\
\hline Response time & Quicker in the non-illusory condition & $t(85)=-20.1, p<.01$ \\
\hline Kanizsa Illusory Contour Task & $\begin{array}{l}2 \times 3 \text { repeated measures ANOVA: Condition (experimental or } \\
\text { control) } \times \text { Angle of Inducer }\left(5,10 \text {, or } 15^{\circ}\right)\end{array}$ & \\
\hline \multicolumn{3}{|l|}{ Accuracy } \\
\hline Main effect of condition & Higher in the control condition & $F(1,87)=19.9, p<.01$ \\
\hline Main effect of angle of inducer & $15^{\circ}>10^{\circ}=5^{\circ}$ & $F(2,174)=21.1, p<.01$ \\
\hline Interaction & Effect of angle of inducer seen in illusory block only & $F(2,174)=7.9, p<.01$ \\
\hline \multicolumn{3}{|l|}{ Response time } \\
\hline Main effect of condition & Quicker in the control condition & $F(1,87)=167, p<.01$ \\
\hline Main effect of angle of inducer & $5^{\circ}<10^{\circ}=15^{\circ}$ & $F(2,174)=42.5, p<.01$ \\
\hline Interaction & Effect of angle of inducer seen in illusory block only & $F(2,174)=4.5, p<.05$ \\
\hline Visual Search Task & $\begin{array}{l}2 \times 3 \text { repeated measures ANOVA: Target Presence (present or absent) } \\
\mathrm{x} \text { Set Size }(5,15 \text {, or } 25)\end{array}$ & \\
\hline \multicolumn{3}{|l|}{ Accuracy } \\
\hline Main effect of target presence & Higher when target was present & $F(1,80)=70.8, p<.01$ \\
\hline Main effect of set size & $5>15>25$ & $F(2,160)=10.1, p<.01$ \\
\hline Interaction & $\begin{array}{l}\text { Performance decreased as the set size increased in target present } \\
\text { condition only }\end{array}$ & $F(2,160)=12.2, p<.01$ \\
\hline \multicolumn{3}{|l|}{ Response Time } \\
\hline Main effect of target presence & Quicker when target was present & $F(1,80)=241.5, p<.01$ \\
\hline Main effect of size & $5<15<25$ & $F(2,160)=304, p<.01$ \\
\hline Interaction & $\begin{array}{l}\text { Response times increased as set size increased in both conditions, but } \\
\text { the effect was larger in the target absent condition }\end{array}$ & $F(2,160)=71.5, p<.01$ \\
\hline Impossible Figures Tests ${ }^{\mathrm{a}}$ & Paired sample $t$-test comparing the possible and impossible trials & \\
\hline Response time & Quicker when figures were possible & $t(87)=6.16, p<.01$ \\
\hline Good form task ${ }^{\mathrm{a}}$ & $\begin{array}{l}2 \text { x } 3 \text { repeated measures ANOVA: Condition (experimental or } \\
\text { control) } x \text { Block Type (Simple 1, Simple 2, or Orthogonal) }\end{array}$ & \\
\hline \multicolumn{3}{|l|}{ Response time } \\
\hline Main effect of condition & Quicker in the control condition & $F(1,84)=66.5, p<.01$ \\
\hline Main effect of block type & Simple $1=$ Simple $2<$ Orthogonal & $F(2,168)=79.5, p<.01$ \\
\hline Interaction & Effect of block type significant in experimental condition only & $F(2,168)=38.4, p<.01$ \\
\hline \multirow[t]{3}{*}{ Rey-Osterrieth Complex Figure } & $\begin{array}{l}\text { Paired samples } t \text {-tests comparing strategy score for copying } \\
\text { and recall }\end{array}$ & $t(88)=16.1, p<.01$ \\
\hline & Correlation between copy and recall accuracy & $r(88)=.23, \mathrm{p}<.05$ \\
\hline & Correlation between copying strategy and recall accuracy & $r(88)=.42, \mathrm{p}<.05$ \\
\hline
\end{tabular}

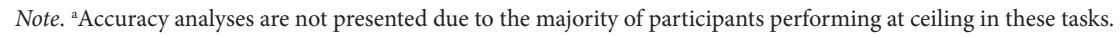




\section{APPENDIX C. FACTOR ANALYSIS OF THE STANDARDIZED RESIDUALS MATRIX}

Preliminary analyses established that the data were suitable for the factor analysis (Bartlett's Sphericity test, $\chi^{2}=498.247, d f=210, p<.001$; determinant of correlation matrix $=.002$; Kaiser-Meyer-Olkin measure of sampling adequacy $=.654$ ). These values are very similar to those obtained in the previous analysis, indicating once more a relatively diffuse pattern of correlations. The analysis of anti-image correlation matrix diagonals brought unsatisfactory results $(<.50)$ for Navon global RT. This variable was excluded from the analysis, which resulted in the improvement of sampling adequacy (Kaiser-Meyer-Olkin = .701).

As in the previous analysis, Kaiser's criterion of eigenvalues greater than 1 resulted in extraction of 7 factors. Together they explained $44.6 \%$ of total variance. Most communality values were again lower than .50 . Only Block Design showed a high communality value (above .80; see Table C1). Coefficients of regression of variables on factors (pattern matrix) and factor loadings, that is coefficients of correlations between variables and factors (structure matrix) are presented in Tables C2 and C3, respectively.

The factorial solution obtained for the correlation matrix of standardised residuals was very similar to that obtained previously for the correlation matrix of raw scores. Correlations between corresponding factors scores from both analyses (estimated using regression methods) were very high ( $r=.90-.99)$. Note, however, that Factor 6 (Cognitive Flexibility) obtained in the previous analysis now appears as Factor 7 (and vice versa). Also the vector of Factor 7 (previously 6) is reversed, that is, high scores on this factor now represent low cognitive flexibility.

Table C4 shows that the matrix of correlations between factors is similar to that obtained in the previous analysis. Good ability to dis-embed (Factor 1) is moderately related to high cognitive flexibility (Factor 7, previously 6), and weakly related to reduced global bias (Factor 4) and high perceptual speed/local bias (Factor 6, previously 7). Moreover, high perceptual speed/local bias is weakly related to high cognitive flexibility.

\section{TABLE C1.}

Communalities in the Second Factor Analysis

\begin{tabular}{lll}
\hline Variables & Initial & Extraction \\
\hline Block Design & .698 & .822 \\
Group Embedded Figures Test accuracy & .522 & .605 \\
Group Embedded Figures Test RT & .401 & .426 \\
VOSP-Silhouettes & .201 & .201 \\
Gestalt Completion Test & .329 & .330 \\
Hidden Patterns Test & .315 & .394 \\
Copying Test & .366 & .379 \\
Spot the Differences Test & .408 & .461 \\
Rey figure: Copying strategy & .300 & .400 \\
Impossible Figures RT & .286 & .488 \\
Muller-Lyer illusory condition accuracy & .266 & .431 \\
Muller-Lyer illusory condition RT & .464 & .654 \\
Visual Search, target present within 25 distractors accuracy & .222 & .290 \\
Visual Search, target present within 25 distractors RT & .279 & .374 \\
Kanizsa illusory condition accuracy & .409 & .682 \\
Kanizsa illusory condition RT & .224 & .281 \\
Good Form experimental orthogonal RT & .430 & .469 \\
Navon Hierarchical Figures Test, incompatible, global acc & .333 & .360 \\
Navon Hierarchical Figures Test, incompatible, local acc & .3705 \\
Navon Hierarchical Figures Test, incompatible, local RT & .370 & .314 \\
\hline
\end{tabular}




\section{TABLE C2.}

Pattern Matrix of the Second Factor Analysis

\begin{tabular}{|c|c|c|c|c|c|c|c|}
\hline \multirow[t]{2}{*}{ Variables } & \multicolumn{7}{|l|}{ Factors } \\
\hline & 1 & 2 & 3 & 4 & 5 & 6 & 7 \\
\hline Embedded Figures acc & .783 & & & & & & \\
\hline Embedded Figures RT & -.588 & & & & & & \\
\hline Block Design & .553 & & & & & & -.384 \\
\hline Copying & .439 & & & & -.312 & & \\
\hline Navon local RT & & .742 & & & & & \\
\hline Navon global acc & & .452 & & & & & \\
\hline Muller-Lyer acc & & & .611 & & & & \\
\hline Kanizsa acc & & & & -.729 & & & \\
\hline Kanizsa RT & & & & .388 & & & \\
\hline Spot the Differences & .375 & & & -.380 & & & \\
\hline Impossible Figures RT & & & & & .581 & & \\
\hline Visual Search acc & & & & & -.390 & & \\
\hline Visual Search RT & & & & & & -.610 & \\
\hline Muller-Lyer RT & & & .431 & & & -.521 & \\
\hline Hidden Patterns & & & & & & .449 & \\
\hline Gestalt Completion & & & & & & & -.548 \\
\hline Navon local acc & & & & & & & -.447 \\
\hline Good Form RT & & & .387 & & & & .423 \\
\hline Rey figure strategy & & .398 & & & & & -.420 \\
\hline VOSP Silhouettes & & & & & & & \\
\hline
\end{tabular}

Note. Coefficients are sorted by size. Those lower than .30 are not displayed.

\begin{tabular}{|c|c|c|c|c|c|c|c|}
\hline \multicolumn{8}{|c|}{ Structure Matrix of the Second Factor Analysis } \\
\hline \multirow[t]{2}{*}{ Variables } & Factors & & & & & & \\
\hline & 1 & 2 & 3 & 4 & 5 & 6 & 7 \\
\hline Block Design & .768 & & & & -.370 & .357 & -.685 \\
\hline Embedded Figures acc & .752 & & & & & & \\
\hline Embedded Figures RT & -.620 & & & & & & .318 \\
\hline Copying & .519 & & & & -.388 & & -.323 \\
\hline Spot the Differences & .516 & & & -.509 & & & -.328 \\
\hline Navon local RT & & .732 & & & & & \\
\hline Navon global acc & & .509 & & -.331 & & & \\
\hline Muller-Lyer acc & & & .575 & & & & \\
\hline Kanizsa acc & & & .358 & -.761 & & & \\
\hline Kanizsa RT & & & & .369 & & & \\
\hline Impossible Figures RT & & .335 & & & .570 & & \\
\hline Visual Search acc & & & & & -.386 & & \\
\hline Muller-Lyer RT & & .375 & .546 & & & -.624 & \\
\hline Visual Search RT & & & & & & -.588 & \\
\hline Hidden Patterns & .401 & & & & & .512 & \\
\hline Gestalt Completion & & & & & & & -.527 \\
\hline Good Form RT & -.316 & & .391 & & & & .525 \\
\hline Navon local acc & .356 & & & & & & -.523 \\
\hline Rey figure strategy & & .360 & & & & & -.476 \\
\hline VOSP-Silhouettes & & & & & & & -.353 \\
\hline
\end{tabular}

Note. Factor loadings are sorted by size. Those lower than .30 are not displayed. Loadings that are statistically significant according to Stevens' (1992) interpretation are highlighted. 
TABLE C4.

Factor Correlation Matrix of the Second Factor Analysis

\begin{tabular}{lllllll}
\hline Factors & 1 & 2 & 3 & 4 & 5 & 6 \\
\hline 1 & & & & & & \\
2 & .06 & & & & & \\
3 & .13 & .11 & & & & \\
4 & $-.25^{*}$ & -.14 & -.08 & -.01 & & \\
5 & -.15 & .04 & -.06 & -.07 & -.12 & $-.28^{* *}$ \\
6 & $.24^{*}$ & -.20 & -.15 & -.05 & .13 & \\
7 & $-.42^{* *}$ & -.07 & .05 & .14 & & \\
\hline Note. ${ }^{*} p<.05$, two-tailed. ${ }^{* *} p<.01$, two-tailed. & & & & & \\
\end{tabular}

